\title{
Genetic interaction network has a very limited impact on the evolutionary trajectories in continuous culture-grown populations of yeast
}

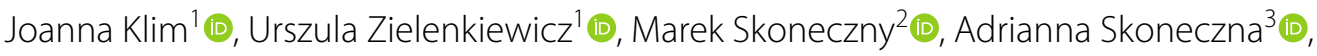 \\ Anna Kurlandzka ${ }^{2}$ (i) and Szymon Kaczanowski ${ }^{4^{*}}$ (D)
}

\begin{abstract}
Background: The impact of genetic interaction networks on evolution is a fundamental issue. Previous studies have demonstrated that the topology of the network is determined by the properties of the cellular machinery. Functionally related genes frequently interact with one another, and they establish modules, e.g., modules of protein complexes and biochemical pathways. In this study, we experimentally tested the hypothesis that compensatory evolutionary modifications, such as mutations and transcriptional changes, occur frequently in genes from perturbed modules of interacting genes.

Results: Using Saccharomyces cerevisiae haploid deletion mutants as a model, we investigated two modules lacking COG7 or NUP133, which are evolutionarily conserved genes with many interactions. We performed laboratory evolution experiments with these strains in two genetic backgrounds (with or without additional deletion of MSH2), subjecting them to continuous culture in a non-limiting minimal medium. Next, the evolved yeast populations were characterized through whole-genome sequencing and transcriptome analyses. No obvious compensatory changes resulting from inactivation of genes already included in modules were identified. The supposedly compensatory inactivation of genes in the evolved strains was only rarely observed to be in accordance with the established fitness effect of the genetic interaction network. In fact, a substantial majority of the gene inactivations were predicted to be neutral in the experimental conditions used to determine the interaction network. Similarly, transcriptome changes during continuous culture mostly signified adaptation to growth conditions rather than compensation of the absence of the COG7, NUP133 or MSH2 genes. However, we noticed that for genes whose inactivation was deleterious an upregulation of transcription was more common than downregulation.
\end{abstract}

Conclusions: Our findings demonstrate that the genetic interactions and the modular structure of the network described by others have very limited effects on the evolutionary trajectory following gene deletion of module elements in our experimental conditions and has no significant impact on short-term compensatory evolution. However, we observed likely compensatory evolution in functionally related (albeit non-interacting) genes.

Keywords: Compensatory evolution, Experimental evolution, Genetic interactions, Yeast, Genomics, Transcriptomics

\footnotetext{
*Correspondence: szymon@ibb.waw.pl

${ }^{4}$ Department of Bioinformatics, Institute of Biochemistry and Biophysics,

Polish Academy of Sciences, Pawińskiego 5a, 02-106, Warsaw, Poland

Full list of author information is available at the end of the article
} original author(s) and the source, provide a link to the Creative Commons licence, and indicate if changes were made. The images or other third party material in this article are included in the article's Creative Commons licence, unless indicated otherwise in a credit line to the material. If material is not included in the article's Creative Commons licence and your intended use is not permitted by statutory regulation or exceeds the permitted use, you will need to obtain permission directly from the copyright holder. To view a copy of this licence, visit http://creativecommons.org/licenses/by/4.0/. The Creative Commons Public Domain Dedication waiver (http://creativeco mmons.org/publicdomain/zero/1.0/) applies to the data made available in this article, unless otherwise stated in a credit line to the data. 


\section{Background}

Genetic interaction networks are the subject of a growing field of scientific research-systems biology. In highthroughput studies the calculation of fitness epistasis has been employed to define interaction networks among gene deletions. The phenomenon of epistasis has been studied for over 100 years and its definition varies in time and between scientific fields. In this study it is considered in terms of the fitness effects of two mutations alone, or in combination, and it is used to describe situations in which those combinations show nonadditive phenotypic effects. Interactions between genes occur when the fitness of a double mutant differs from the additive expectation based on the individual fitness effects of the mutations. Epistasis is positive when mutations in two genes cause an organism to exceed the fitness predicted from individual effects of deleterious mutations on the organism, and it is negative when mutations cause the organism to fall below the predicted fitness. Genetic interactions identify functional relationships between genes and functional modules. Functional modules are groups of genes (related by genetic interactions) that participate in the same biological process.

Genetic interaction networks based on fitness epistasis also contain information regarding adaptive landscapes, which means that fitness data show whether in the background of a given deletion mutant a deletion of another gene is beneficial or deleterious. In the early 1920s, Ronald Fisher pioneered the notion that adaptation is, on the whole, a hill-climbing process. In other words, adaptation proceeds through a progressive accumulation of beneficial mutations [1]. Soon after, Sewall Wright proposed in a seminal paper that the relationship between genotypes could be visualized (or described) as a landscape [2]. The fitness is the "height" of the landscape, while the genotypes or phenotypes are points in the multidimensional space located beneath the landscape. During evolution, genotypes achieve local peaks of fitness by gradual step mutations. The evolutionary theories predict that different populations evolve toward a stable outcome unless the adaptive peak is constantly in motion i.e. landscape is unstable [3]. If a genetic interaction network is stable, it could be expected that the landscape resulting from that network has an impact on the trajectory of compensatory evolution in similar conditions and similar genetic backgrounds. The history of compensatory evolution studies is as old as microbial experimental evolution itself (for a review see [4]). Once a deleterious mutation is introduced in a given population, its negative effect on fitness can be alleviated through compensatory evolution. Thus, compensatory evolution is an adaptive process in which specific mutations are driven to fixation to suppress or mask the effect of a deleterious mutation.
In this paper, we investigated whether the genetic interaction network has an impact on the evolution of biological functional modules. We expected that loss of function of one component of such modules would lead to evolutionary reorganization of the cellular machinery. Simultaneously, we verified the impact of compensatory evolution on modules of genetic interactions. As an experimental model, we utilized the budding yeast Saccharomyces cerevisiae, which is the most thoroughly genetically characterized eukaryotic microorganism. In this model, the genetic interaction network is well characterized [5]. It has been shown that nonlethal deleterious mutations are widespread in populations $[6,7]$. Two large-scale evolutionary studies suggest that such mutations are frequently compensated for by other mutations elsewhere in the genome $[8,9]$, a statement which is supported by other findings [10-13].

We tested the stability of two functional modules associated with two evolutionarily conserved genes with many interactions: COG7, which encodes a protein involved in vesicular transport, and NUP133, which encodes a protein engaged in nucleocytoplasmic transport. Using whole-genome sequencing and microarray techniques, we analyzed the evolutionary trajectory in $\operatorname{cog} 7 \Delta$ and nup $133 \Delta$ haploid mutants subjected to experimental evolution in continuous culture in a non-limiting minimal medium. Continuous cultures assure the stability of environmental conditions and the metabolic state of cells whereas a chemically-defined medium ensures reproducibility of results. Moreover, a defined medium minimizes the number of variables thus facilitating the exploration of those important for the given study. This is particularly advantageous when whole transcriptome studies are performed, which is one of the elements of this research $[14,15]$.

We came to the conclusion that the supposedly compensatory inactivation of genes in the evolved strains was very rarely in accordance with the established fitness landscape and only a few changes in the transcriptomes of the evolved yeast populations were in keeping with predictions. A substantial majority of the inactivations were in fact predicted to be neutral on the basis of the landscape of the interaction network [16]. However, we identified mutations in genes that are functionally related to COG7 or NUP133 and in new genes that are likely involved in adaptations to continuous culture and medium conditions.

\section{Results}

Experimental evolution-general description

In order to check whether the genetic interaction network has an impact on evolution of biological functional modules, we performed two sets of experiments. 
The evolving yeast strains were devoid of either the COG7 or the NUP133 gene. These evolutionarily conserved genes [17-20], were selected because $\operatorname{cog} 7 \Delta$ and nup $133 \Delta$ mutants exhibited enhanced fitness while combined with some other deletion mutants in the high throughput Synthetic Genetic Array (SGA) assay of genetic interaction networks [16]. According to the BioGRID repository (https://thebiogrid.org [21]), both genes exhibit numerous genetic interactions: COG7352 and NUP133-530. Based on the BioGRID database statistics available for S. cerevisiae S288C strain, there are 443,432 non-redundant genetic interactions among the 5,962 unique yeast genes, therefore each gene exhibits ca. 74 genetic interactions, on average. According to data from Costanzo et al. [16], COG7 is involved in 248 and NUP133 in 362 interactions in comparison to 165 on average. Taken together, these data imply that COG7 and NUP133 genes participate in 1.5- to sevenfold more genetic interactions than the average gene. Thus, the likelihood of observing compensatory mutations arising in other genes seemed high even in a short-term experiment.

The COG7 gene encodes an element of the oligomeric Golgi (COG) complex. The COG complex organizes core vesicular trafficking to and within the Golgi apparatus and is also involved in protein glycosylation. It is remarkable for the number of interactions, and a lack of nearly any of its elements significantly affects numerous cellular processes [22]. The Cog7 subunit forms a binary complex with Cog5 [23]. Their interaction is conserved from yeast to humans and its disruption causes glycosylation defects [24]. Nup133, a component of the nuclear pore complex (NPC), is an element of the coat nucleoporin subcomplex (CNC) [25, 26]. Nup133 has multiple functions mainly linked to RNA export and NPC assembly [27, 28]. It is also involved in the functioning of the mitotic spindle by recruiting centromeric CENP-F to NPCs in the prophase and maintaining the association of the centrosome with the nuclear envelope at mitotic entry [29].

We also performed a second set of experiments designed to speed up the evolution, in which double mutants $\operatorname{cog} 7 \Delta$ msh $2 \Delta$ and nup $133 \Delta$ msh $2 \Delta$ were used. The lack of $M S H 2$ gene increases the frequency of mutations and we assumed that introducing $m s h 2 \Delta$ into $\operatorname{cog} 7 \Delta$ or nup133 could increase the rate of appearance of beneficial variants by increasing the dynamics of mutation rate.

Before the continuous culture experiments were run, growth rates of knockout strains were measured in comparison to the wild-type strain in the non-limiting minimal medium used in further studies (Additional file 1). As expected, all mutants had increased doubling times (0.4-23.6\%) in comparison to the wild-type.
The studied strains were cultivated in parallel with three replicates for each strain, resulting in 12 independent continuous cultures. To detect adaptations unrelated to the presence of the $\operatorname{cog} 7 \Delta$ or nup $133 \Delta$ deletions, we performed similar evolutionary experiments for control strains; the parental W303 strain and the msh2 $\Delta$ strain, both in triplicate. The cell culture density was maintained in a stable state of $5.2 \pm 1.1 \times 10^{7}$ cells per $\mathrm{mL}$, the density equivalent to the late exponential phase of batch culture in the same medium. The experiments were ended due to the appearance of flocculation. All non-mutator populations $(M S H 2)$ were propagated for approximately 200 generations, and the mutator $(m s h 2 \Delta)$ ones for ca. 350 generations (Fig. 1). Then, the genomes and transcriptomes of evolved populations were determined.

Because it was reported that in some evolutionary experiments, yeast cells can switch their ploidy ([30-32], for a review see [33]), we evaluated the ploidy of evolved populations by DNA content analyses using flow cytometry and we found that haploidy was distinctly dominant in all populations. Analyses were performed for all biological replicates, and representative DNA content profiles are shown in Additional file 2.

\section{Mutations in evolved yeast populations}

To identify the genetic changes in the evolved populations complete genomes of 17 independently evolved populations (one of the evolved msh $2 \Delta$ population could not be processed due to technical reasons) were sequenced and compared with the genomes of corresponding ancestor strains sequenced de novo. The average coverage for a population whole-genome sequencing across all samples was $113 \times$. Variants supported by less than 10 reads across a given population were removed. To filter for high-frequency variants, a 50\% mutation frequency threshold (on a population scale) was applied. Figure 2 shows summarized data obtained for each population studied. At the scale of whole populations, we identified ca. 100-130 new mutations in non-mutator strains and ca. 200-350 mutations in the mutator ones. Next, we calculated fixed mutation rate that was defined as an average number of mutations (with a frequency threshold $\geq 50 \%$ ) identified in each yeast strain, per base, per replication cycle (mut/nuc/rep). The fixed mutation rates were similar in the $\operatorname{cog} 7 \Delta$, nup $133 \Delta$, and WT strains. As expected, the fixed mutation rates of the control $m s h 2 \Delta$ and the $\operatorname{cog} 7 \Delta m s h 2 \Delta$ and nup $133 \Delta$ msh $2 \Delta$ strains were higher than in non-mutator ones. The vast majority of all mutations were localized to tandem repeats (TRs), and numerous were found in putative promoters (Fig. 2). For one mutation in an ORF, there were on average ten (nonmutators) or eight (mutators) mutations in promoter regions. 


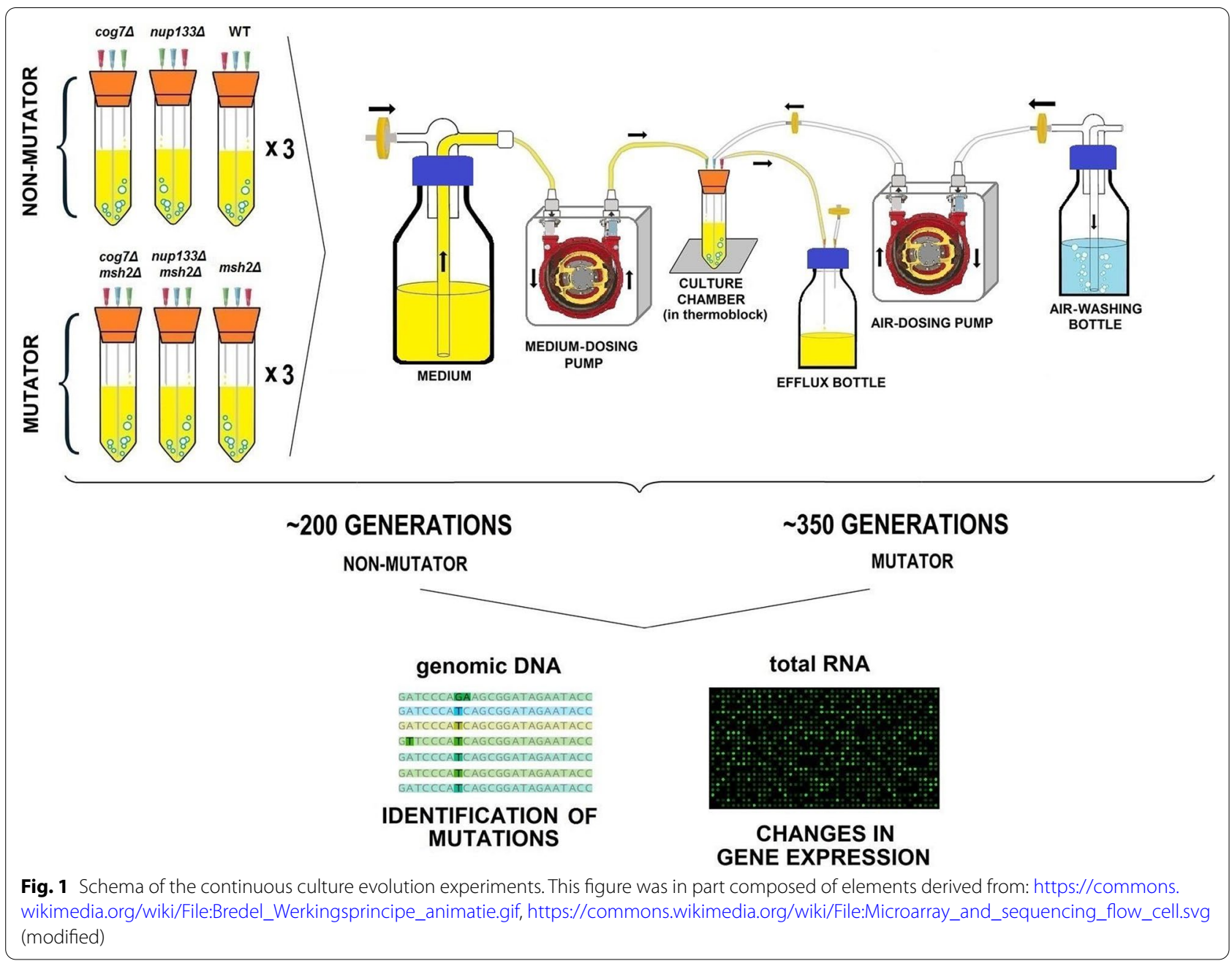

In further analyses we only considered single nucleotide polymorphisms (SNPs) and short insertion/deletion events. Intergenic mutations and those identified in TRs regions were not included. Because there were only small differences in the number and types of mutations between different biological replicates for a given yeast strain, they were combined for further analysis. Point mutations in open reading frames (ORFs), putative promoter ( $5^{\prime}$ upstream regions - up to 500 nucleotides), and terminator regions $\left(3^{\prime}\right.$ downstream regions-up to 250 nucleotides) were analyzed separately. Summarized data are presented in Table 1 and Additional file 3: Table S3, Additional file 4: Table S4 and Additional file 5: Table S5 that show detailed information.

Data combined for three biological replicates. Intergenic mutations and those identified in TRs regions not included. Mutation frequency threshold $\geq 50 \%$.

In the evolved $\operatorname{cog} 7 \Delta$ and nup $133 \Delta$ populations we found few unique nonsynonymous substitutions, one (in $M E C 1$ ) in $\operatorname{cog} 7 \Delta$ population 3 , and three (in CAN1,
PFK27, and WHI2) in nup1334 population 1 and 2. According to the Costanzo et al. [16] databases neither MEC1 interacts with COG7 nor CAN1, PFK27 or WHI2 with NUP133. A similar number of unique mutations was detected in the evolved wild-type populations, where we identified mutations in MSY2, URE2, and DAL82, of which only two were nonsynonymous (Table 1 and Additional file 3: Table S3).

In the evolved $\operatorname{cog} 7 \Delta m s h 2 \Delta$ populations, 43 unique mutations were identified in ORFs, and 36 of them alter the amino acid sequence of encoded proteins (Table 1 and Additional file 4: Table S4). In the evolved nup1334 $m s h 2 \Delta$ populations, 36 unique ORF mutations were identified, of which 24 were non-synonymous (Table 1 and Additional file 4: Table S4).

In the $\operatorname{cog} 7 \Delta m s h 2 \Delta$ populations, the set of genes bearing nonsynonymous mutations could be divided into six subgroups according to their biological function (except for two uncharacterized ORFs, YPL247C and YPL277C), shown in Table 2 (for more details, see Additional file 6), 


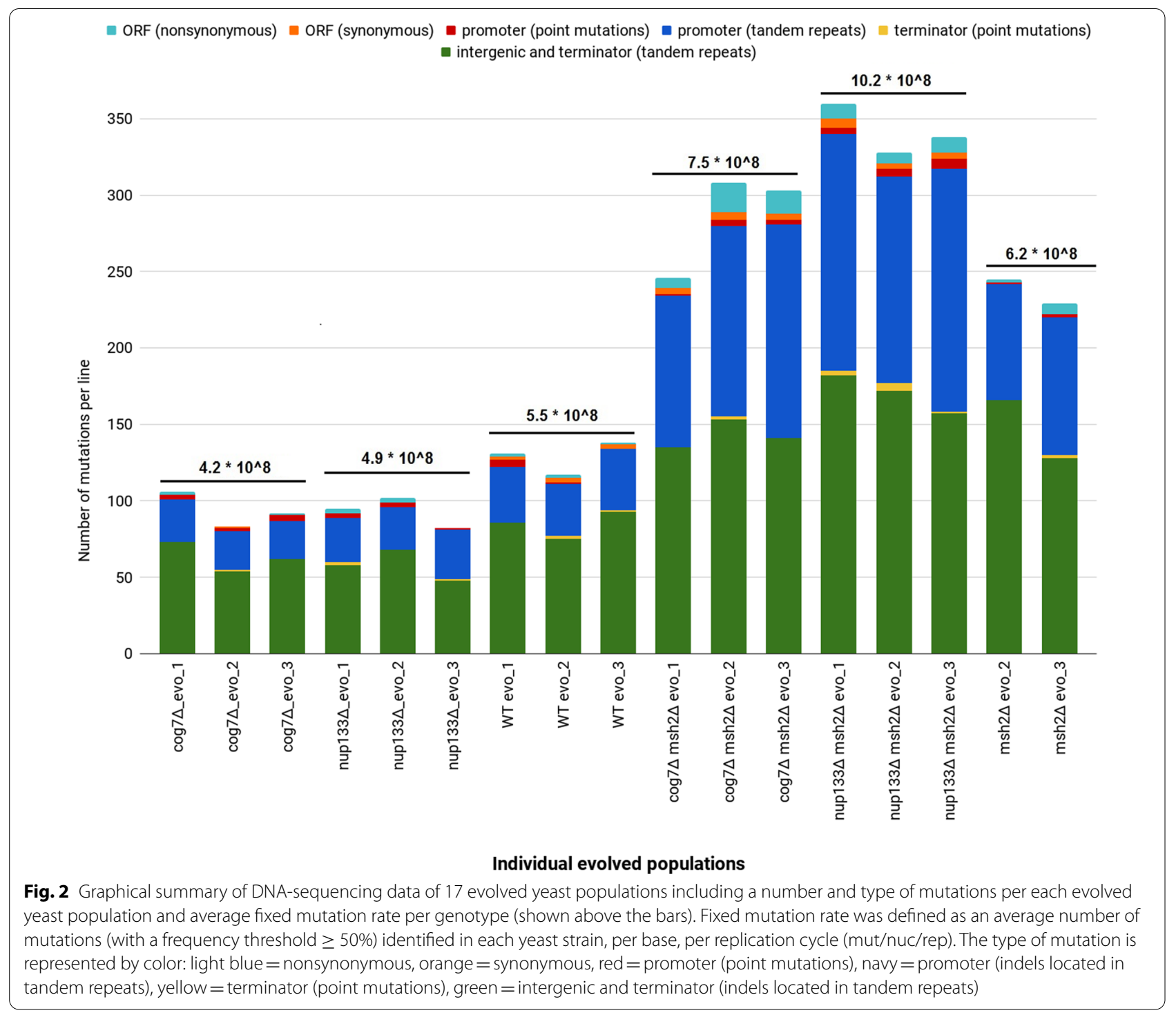

Table 1 Characteristics of point mutations identified in evolved yeast strains

\begin{tabular}{|c|c|c|c|c|c|c|}
\hline \multirow{3}{*}{ Strain } & \multicolumn{6}{|c|}{ Mutations } \\
\hline & \multicolumn{2}{|l|}{ ORFs } & \multicolumn{2}{|c|}{ Putative promoter regions } & \multicolumn{2}{|c|}{$\begin{array}{l}\text { Putative terminator } \\
\text { regions }\end{array}$} \\
\hline & Total & Genotype-specific $^{b}$ & Total & Genotype-specific $^{\mathbf{b}}$ & Total & $\begin{array}{l}\text { Genotype- } \\
\text { specific }^{b}\end{array}$ \\
\hline $\operatorname{cog} 7 \triangle$ & 4 & $1\left(1^{\mathrm{a}}\right)$ & 2 & 1 & 2 & 1 \\
\hline nup $133 \triangle$ & 5 & $3\left(3^{\mathrm{a}}\right)$ & 2 & 1 & 6 & 5 \\
\hline WT & 4 & $3\left(2^{\mathrm{a}}\right)$ & 4 & 3 & 4 & 3 \\
\hline $\operatorname{cog} 7 \Delta m s h 2 \triangle$ & 44 & $43\left(36^{a}\right)$ & 8 & 8 & 3 & 2 \\
\hline nup $133 \Delta m s h 2 \triangle$ & 36 & $36\left(24^{a}\right)$ & 15 & 15 & 8 & 7 \\
\hline$m s h 2 \Delta$ & 8 & $7\left(7^{a}\right)$ & 3 & 3 & 2 & 2 \\
\hline
\end{tabular}

\footnotetext{
${ }^{a}$ Nonsynonymous

${ }^{b}$ Unique to given strain in terms of given experimental group (non-mutator or mutator)
} 
Table 2 Gene ontology classification of mutated genes according to their biological meaning

\begin{tabular}{|c|c|c|}
\hline Biological meaning & $\operatorname{cog} 7 \Delta m s h 2 \Delta$ & 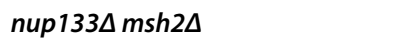 \\
\hline Cell wall and cell division & DMA2, ELM1, SKM1 & DMA1, GIC1, SCW4 \\
\hline Cellular metabolism & AMF1, DAK2, GLN1, GNA1, HXK1, ICL1, SEO1, SHM2, SHP1, SOL4, TKL1 & CAN1, CEX1, EFT2, SAM2 \\
\hline Endocytosis & ART5, ECM21 & \\
\hline Genome maintenance & AMN1, EXO5, HUR1, IRR1, NET1, PIF1, SAP3O & APC5, GIC1, MEC3, RIM15, RSC1, SWI1 \\
\hline Golgi/ER-associated & HSP104, KRE5, PMR1, TRX2 & PRK1, SLA2 \\
\hline Histone modification & & $A C C 1, B R E 1$ \\
\hline Peroxisome-associated & & INP1, PEX21 \\
\hline Protein folding & & EMP65, HSP60, IBA57, TAH1 \\
\hline Transcription, translation & ACE2, MRPS5, PAB1, PRP2, RPL4B, SSN3, WAR1 & \\
\hline
\end{tabular}

however, no enrichment of gene ontology (GO) terms was found. In the nup133 $\operatorname{msh} 2 \Delta$ strain mutated genes belonged to seven functional groups (Table 2, for details, see Additional file 7). Again, no GO term enrichment was found.

It should be noticed that $\operatorname{cog} 7 \Delta m \operatorname{sh} 2 \Delta$ and nup133 $\Delta$ $m s h 2 \Delta$ populations share some enriched groups e.g., cellular metabolism, and genome maintenance.

In the control $m s h 2 \Delta$ evolved strain only a small number of uniquely mutated genes was found: $B R R 2, D R N 1$, MDN1, PMD1, RPL42B, URE2, and YBT1 thus GO enrichment analysis was not performed.

\section{Putative adaptive mutations in evolved strains}

We verified whether the loss-of-function mutations acquired during our continuous culture experiments fit in the yeast genetic network described by Costanzo et al. [16], which has been used as a model of the fitness landscape. Such mutations are likely to have a universal beneficial impact on the deletion mutants subjected to the experiments. We assumed that the loss of function of a second gene has a statistically significant impact on the fitness of the original deletion mutant if the absolute value of the difference between the fitness of the single and the double deletion mutant is higher than three times the standard deviation of the fitness of the double mutant. Among changes present in the evolved mutant strains there were few causing nonsense mutations leading to protein truncation caused by premature stop codons. One such mutation (in WHI2) was found in the nup133A population 1, but according to Costanzo et al. [16] inactivation of WHI2 has no impact on fitness of nup133A. No putative loss-of-function mutations were found in $\operatorname{cog} 7 \Delta$ populations. In the double mutant $\operatorname{cog} 7 \Delta m s h 2 \Delta$ three putative loss-of-function mutations were found, $A C E 2$ (in population 3), ECM21 and

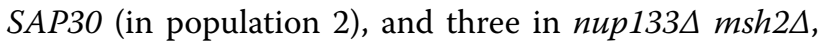
MEC3, RIM15 and TAH1 (in population 3). According to Costanzo et. al. [16], inactivation of $A C E 2$ and ECM21 has no impact on fitness of neither $\operatorname{cog} 7 \Delta$ nor $m s h 2 \Delta$, while inactivation of SAP3O is deleterious both for the $\operatorname{cog} 7 \Delta$ and $m s h 2 \Delta$ mutants. Loss of function of $M E C 3$ has no impact on the fitness of nup133A and $m s h 2 \Delta$ while inactivation of RIM15 is beneficial and inactivation of TAH1 is deleterious when combined with $m s h 2 \triangle$. In the control $m s h 2 \Delta$ evolved strain only the URE2 gene was truncated (population 2). Ure2 participates in nitrogen catabolite repression [34]. Deletion of URE2 has no impact on the fitness of $m s h 2 \Delta$ in the genetic interaction network.

Thus, the supposedly compensatory inactivation of genes in the evolved populations followed the expectation (i.e., was in accordance with landscapes derived from known genetic interactions [16]) only one in eight cases. In five cases no impact on mutant fitness was predicted, and in two cases gene inactivation might cause fitness decrease. Thus, a substantial majority of the inactivations were in fact predicted to be neutral.

What is more, we did not observe any trend of mutations accumulation in genes that participate in the same functional module as primarily deleted COG7, NUP133 or $M S H 2$, respectively (documented in Table 3). Also, the number of genes showing positive and negative interactions with the tested genes was similar (data not shown).

The analysis was based on Costanzo et al. [16] genetic interaction network data and two filtration thresholds were applied. Only genes mutated in ORFs and promoter regions (in parentheses) were analyzed.

Thus, we did not find correlations between neither MSH2, COG7 nor NUP133 and mutated genes in terms of genetic interactions. The identified genes are not the parts of the same modules as originally deleted ones and they do not correlate with the fitness landscape of genetic interaction network. Thus, the fitness landscape does not seem to govern the process of evolution of tested deletion mutants. 
Table 3 A number of genotype-specific genes mutated in the course of evolution exhibiting genetic interactions (GIs) with primarily deleted COG7, NUP133 or MSH2, respectively

\begin{tabular}{|c|c|c|c|c|}
\hline \multirow[t]{2}{*}{$\begin{array}{l}\text { Primarily } \\
\text { deleted } \\
\text { gene }\end{array}$} & \multirow[t]{2}{*}{ Evolved strain } & \multicolumn{2}{|c|}{$\begin{array}{l}\text { Genes exhibiting genetic } \\
\text { interaction/s with } \\
\text { primarily deleted gene }\end{array}$} & \multirow[t]{2}{*}{$\begin{array}{l}\text { Mutated } \\
\text { genes }\end{array}$} \\
\hline & & Lenient $^{\mathrm{a}}$ & $\begin{array}{l}\text { Stringent } \\
\text { confidence }^{b}\end{array}$ & \\
\hline \multirow[t]{2}{*}{ COG7 } & $\operatorname{cog} 7 \triangle$ & 0 & 0 & 2 \\
\hline & $\operatorname{cog} 7 \Delta m s h 2 \Delta$ & $5(1)$ & 0 & $51(8)$ \\
\hline \multirow{2}{*}{ NUP133 } & nup133ム & 0 & 0 & 4 \\
\hline & nup $133 \Delta$ msh2 & $8(4)$ & $3(1)$ & $51(15)$ \\
\hline \multirow[t]{3}{*}{ MSH2 } & $\operatorname{cog} 7 \Delta m s h 2 \triangle$ & 6 & 1 & $51(8)$ \\
\hline & nup $133 \Delta$ msh2 2 & 3 & 2 & $51(15)$ \\
\hline & $m s h 2 \Delta$ & 0 & 0 & $10(3)$ \\
\hline
\end{tabular}

${ }^{a}(P<0.05)$

${ }^{b}(P<0.05$ and $G I S>0.16$ or $<-0.12)$

The genetic interaction network we based our study on was determined for one specific growth condition and one $S$. cerevisiae strain. It is quite likely that upon different conditions different interactions will be revealed [35]. However, since a significant conservation of GIs and GI network structure has been reported even between distant yeast species [36, 37], it seems less likely that it would completely change the overall image of the network itself.

To understand the mechanisms of adaptation of studied mutants we searched through all genes mutated in coding sequences hoping to identify unanticipated mutations. In result, we identified mutations in genes functionally related to COG7 or NUP133. We also identified mutations in genes involved in adaptations to the chemostat conditions, identified by other researchers. Since our experimental continuous culture conditions resembled a chemostat, we could expect such changes. They are briefly described below.

In the evolved $\operatorname{cog} 7 \Delta$ population we found the mutation leading to a change in the Mec1 protein. In nup133A - mutations leading to changes in Can1, Pfk27, Whi2. These proteins play important roles in DNA repair, sugar metabolism, and general stress response but are not known to be, directly or indirectly, linked to COG7 or NUP133, respectively. In the evolved $\operatorname{cog} 7 \Delta m s h 2 \Delta$ and nup $133 \Delta m s h 2 \Delta$ populations we selected a few putative compensatory mutations. The characteristics of the respective proteins and amino acid changes that resulted from identified mutations are given in Table 4. In $\operatorname{cog} 7 \Delta m s h 2 \Delta$ we found mutations in PMR1 and TRX2 (population 2), likely related to COG7. We assume that mutations in these genes, if they enhanced the activity of the encoded proteins, could compensate for the COG7 loss. Pmr1 protein delivers calcium and manganese ions to the Golgi. Both ions are required for proper processing and trafficking of polypeptides through the secretory pathway [38]. It has been reported that Pmr1 plays a role in the sorting of secreted proteins at the trans-Golgi network/late Golgi membranes and in glycosylation since PMR1 inactivation led to some perturbations of the glycosylation [39]. What is more, according to the data deposited in the BioGRID, PMR1 inactivation combined with deletion of some of the COG genes causes severe growth defects. Therefore, it seems that the Pmr1 and Cog proteins are closely related functionally. $\operatorname{Tr} x 2$ is an element of the thioredoxin system that plays an essential role in cell protection against oxidative stress induced by reactive oxygen species (ROS) and participates in cell repair. Interestingly, the Trx2 protein is also required for vacuole inheritance and ER-Golgi transport where it participates in the retrieval of resident ER proteins cycling between the Golgi and the ER [40]. Therefore, it can be postulated that Trx2 has an impact on the Golgi-ER communication and could alleviate the vesicle trafficking defects caused by a lack of Cog7. In the nup $133 \Delta m s h 2 \Delta$ derived populations, we found five mutated genes that might be functionally related to NUP133. Four of them: ACC1 (population 2), BRE1, RSC1 (population 3) and $S W I 1$ (population 1) encode proteins engaged in NPC stabilization, transcription and chromatin silencing [4144 ]. Because Nup133 is also involved in these processes [45-47], it is likely that the mutated genes could, to some degree, compensate for the NUP133 loss. The fifth protein, Cex1, interacts directly with NPCs and participates in the tRNA export [48]. Thus, the mutation in CEX1 (identified in population 3 ) is likely to compensate for some functions compromised in nup1334.

Because most of the amino acid changes were located in domains or motifs important for the function of the respective proteins it is likely that they caused significant functional changes. We suggest that the mutations identified in the above genes could be compensatory by alleviating the fitness loss due to the deletion of COG7 or NUP133. The missense mutations, by enhancing growth of evolved mutants, may facilitate the restoration of their fitness. However, the fact that not all evolved populations of a given strain carry such mutations suggests that alternative mechanisms of fitness compensation were achieved, or other compensatory events took place.

The majority of mutations occurred in genes involved in basic cellular processes. It is well known that culturing in a chemostat, which our experiments emulated (constant growth conditions) except for the absence of nutrient limitation, often results in altered cellular strategies independent of the original genotype but rather 
Table 4 Putative compensatory mutations in evolved $\operatorname{cog} 7 \Delta m s h 2 \Delta$ and nup $133 \Delta$ msh2 $\Delta$ mutator populations

\begin{tabular}{|c|c|c|c|c|c|c|c|}
\hline $\begin{array}{l}\text { Primarily } \\
\text { deleted } \\
\text { gene }\end{array}$ & Mutated gene & Function & aa change & aa position & PFAM Domain (aa) & $\begin{array}{l}\text { Motif } \\
\text { (ELM prediction) }\end{array}$ & $\begin{array}{l}\text { Putative connection } \\
\text { with deleted gene }\end{array}$ \\
\hline \multirow[t]{2}{*}{ COG7 } & PMR1 & $\begin{array}{l}\text { Ion transporting } \\
\text { ATPase }\end{array}$ & $\mathrm{F} \rightarrow \mathrm{C}$ & 926 & $\begin{array}{l}\text { PF00689 } \\
\text { P-type ATPase, trans- } \\
\text { membrane domain } \\
(762-934)\end{array}$ & & $\begin{array}{l}\text { Required for } \mathrm{Ca}^{2+} \text { and } \\
\mathrm{Mn}^{2+} \text { transport into } \\
\text { Golgi }\end{array}$ \\
\hline & TRX2 & $\begin{array}{l}\text { Cytoplasmic thiore- } \\
\text { doxin }\end{array}$ & $M \rightarrow V$ & 40 & $\begin{array}{l}\text { PF00085 Thioredoxin } \\
\text { domain }(10-100)\end{array}$ & & $\begin{array}{l}\text { Required for ER vesicle } \\
\text { fusion with the Golgi }\end{array}$ \\
\hline \multirow[t]{5}{*}{ NUP133 } & $A C C 1$ & $\begin{array}{l}\text { Regulates histone } \\
\text { acetylation; } \\
\text { required for syn- } \\
\text { thesis of long-chain } \\
\text { fatty acids that } \\
\text { were proposed to } \\
\text { stabilize the NPC } \\
\text { [41] }\end{array}$ & $\mathrm{H} \rightarrow \mathrm{R}$ & 2068 & $\begin{array}{l}\text { PF01039 } \\
\text { Acetyl-CoA carboxy- } \\
\text { lase (1574-2130) }\end{array}$ & & $\begin{array}{l}\text { Nup133 also plays a } \\
\text { role in transcription } \\
\text { regulation and chro- } \\
\text { matin silencing }\end{array}$ \\
\hline & BRE1 & $\begin{array}{l}\text { Required for meth- } \\
\text { ylation of selected } \\
\text { histones [42] }\end{array}$ & $\mathrm{L} \rightarrow \mathrm{S}$ & 599 & & & \\
\hline & $\mathrm{RSCl}$ & $\begin{array}{l}\text { Regulates nucleo- } \\
\text { some positioning } \\
\text { and transcription } \\
\text { regulation [43] }\end{array}$ & $A \rightarrow V$ & 98 & $\begin{array}{l}\text { PF00439 } \\
\text { Bromodomain } \\
\quad(31-98)\end{array}$ & & \\
\hline & SWI1 & $\begin{array}{l}\text { Regulates transcrip- } \\
\text { tion by remodeling } \\
\text { chromatin [44] }\end{array}$ & $\mathrm{T} \rightarrow \mathrm{N}$ & 15 & & $\begin{array}{l}\text { GSK3 phosphoryla- } \\
\text { tion recognition } \\
\text { site }\end{array}$ & \\
\hline & CEX1 & $\begin{array}{l}\text { Component of } \\
\text { nuclear tRNA } \\
\text { export pathway } \\
\text { [48] }\end{array}$ & $\mathrm{A} \rightarrow \mathrm{T}$ & 468 & & & $\begin{array}{l}\text { Associates with NPCs } \\
\text { by interacting with } \\
\text { Nup116p }\end{array}$ \\
\hline
\end{tabular}

Putative compensatory mutations in evolved $\operatorname{cog} 7 \Delta m s h 2 \Delta$ and nup $133 \Delta$ msh2 2 mutator populations

associated with the response to the environment (for a review see [49]). In our study, they are likely represented by changes not related to the original deletion. These changes may hinder connecting genotype to the observed mutations, but nonetheless, they provide valuable information about the spectrum of mutations that are adaptive in a specific environment. They also validate the conducted experiment indicating that it was carried out long enough to allow adaptation to growth conditions.

In the non-mutator strains, we identified mutations in the genes HOG1 and WHI2 linked before to the adaptation to chemostat conditions [50]. The Hog1 protein plays an essential role in multiple stress conditions (for a review see [51]) and Whi2 is essential for general stress response associated with cell cycle arrest [52]. We found nonsynonymous mutations (both frameshift and missense) in HOG1 in wild-type (population 1 and 2) and $\operatorname{cog} 7 \Delta$ (population 1) (Additional file 3). One of them resulted in a stop codon, the second mutation caused E186K substitution. In $\operatorname{cog} 7 \Delta$ the mutation leading to R290K substitution was identified. In the gene WHI2 missense and nonsense mutations occurred in nup133A populations, i.e., mutation causing substitution Q387* in population 1 and W273L in population 2 (Additional file 3). The presence of these mutations, likely inactivating Hog1 and Whil, indicates that experimental conditions did not trigger stress responses. At present, we cannot explain putative advantageous qualities of the observed changes.

Mutations in URE2 (WT population 2), PFK27 (nup133A population 1), BUL1 (cog7A population 1, and nup133 population 2), and MSY1 (WT population 1 and $3)$ are likely to be adaptive. These genes encode proteins engaged in fructose metabolism (PFK27), regulation of nitrogen utilization (URE2), aa-tRNA synthesis (MSY1), and amino acid uptake (BUL1). Thus, in the non-mutator strains, the adaptations indicate that the environment caused a stronger selective pressure than did the introduction of gene deletions.

In the mutator populations, two genes related to continuous culture adaptation were affected: RIM15 in nup133A msh2 2 (population 3), and ACE2 in $\operatorname{cog} 7 \Delta$ $m s h 2 \Delta$ (population 3). Rim15 protein activates transition to the G0 phase in response to starvation [53], and its mutations have been described in a variety of nutrient-limited chemostat experiments [50, 54-57]. ACE2 
encodes a cell cycle-regulated transcription factor [58]. What is more, mutations in ACE2 likely contribute to the evolution of aggregation phenotypes [59]. Altogether three genes engaged in cell cycle regulation (ACE2, WHI2 and RIM15) and associated with the adaptation to growth conditions were mutated.

Besides the above mutations, we found other potentially growth conditions-adaptive ones, in genes related to basic metabolism. It is likely that the mutations identified in PRO3 and URE2 ( $m s h 2 \triangle$ and wild-type), AMF1, DAK2, GLN1, GNA1, HXK1, ICL1, PRO3, SEO1, SOL4 and TKL1 (cog7A msh2A) and PEX21 and SAM2 (nup133Amsh2A) could have beneficial effects on yeast growth in continuous culture in non-limiting minimal medium (for details see Additional file 6 and Additional file 7).

To sum up, we did not find compensatory gene inactivations linked to COG7 or NUP133. Our genomic data indicate that mutations do not tend to accumulate in genes belonging to a given functional module. Instead, we identified a few putative compensatory mutations related to COG7 or NUP133 and compensating for their loss, but not included in the Costanzo et al. [16] genetic interaction network. Substantially more mutations were linked to general adaptations to growth conditions.

\section{Parallel evolution in the evolving yeast populations}

The data from repeated experiments were pooled to facilitate the analyses discussed above. However, this approach prevented us from detecting mutations shared by different populations evolved from the same ancestor, i.e., cases of parallel evolution. Thus, in the next step, we re-examined ORF mutations in each population separately. Table 5 shows that in the non-mutators at least two populations which evolved from the same genotype shared mutations in one (WHI2-in nup133A) or two (MSY1 and HOG1-in wild-type) genes. As already mentioned, mutations in WHI2 are speculated to provide a fitness advantage under certain environments or in combination with other compensatory mutations $[8,60]$ whereas a role of mutations in HOG1 remains unclear.

Although in the msh $2 \Delta$ populations more mutations occurred, as expected, they were not more reproducible between replicates than in the non-mutator ones. The only shared mutations in $\operatorname{cog} 7 \Delta m s h 2 \Delta$ populations were in $S E O 1$ encoding putative transmembrane transporter and in $C D C 3$ encoding a component of the septin ring (Table 5). This indicates that parallel evolution within a given yeast strain was overall rare in the evolving yeast populations.

Interestingly, we identified four genes that were mutated more than once across all yeast populations i.e., BUL1 ( $\alpha$-arrestin, a component of the Rsp5p E3-ubiquitin ligase complex), $P R O 3$ (catalyzes the last step in proline biosynthesis), URE2 (glutathione peroxidase involved in regulating cellular nitrogen utilization), and already mentioned HOG1. Mutations in these genes might be beneficial in our experimental conditions, regardless of genetic background.

\section{Transcriptomic changes in evolved populations}

In parallel with the whole population sequencing of evolved yeast cell populations, we performed transcriptome analyses of the same samples. Here, we aimed to reveal if the transcriptome changes are directly linked to mutations in 5 ' upstream regions. We envisaged that changes in gene expression levels within the continuously cultured cell population may have compensatory characteristics or even that some of the differentially expressed genes (DEGs) belong to COG7 or NUP133 interaction modules.

To reject changes in gene expression occurring due to rapid shift in conditions at the onset of continuous culture, we compared the transcriptomes of the cell population samples harvested after about 35 generations, i.e., shortly after reaching the steady-state, with the transcriptomes of final, adapted populations after about 200 generations (for WT, $\operatorname{cog} 7 \Delta$ and nup 133 4 ) or after about 350 generations (for $m s h 2 \Delta, m s h 2 \Delta \operatorname{cog} 7 \Delta$ and $m s h 2 \Delta$ nup 133A). Agilent Yeast v2 microarray and Cy3 Cy5 twocolor labeling were employed in this experiment (see Materials and Methods for more details). Hereafter, for brevity, we call the results of these comparisons as adaptive transcriptomes.

First, we analyzed the similarities between adaptive transcriptomes of individual biological replicates within each genotype and between genotypes. We employed Euclidean distance as a measure of this similarity and the results are shown in Additional file 8, A and B.

This analysis revealed slightly higher level of similarity between adaptive transcriptomes of biological replicates of WT and $\operatorname{cog} 7 \Delta$ genotypes than between those of the remaining genotypes, but in general these differences were not statistically significant ( $\mathrm{p}$-value calculated with Student $\mathrm{t}$-test was between 0.44 and 0.81 ). The similarities between averaged transcriptomes of each genotype (Additional file 8, B) were on the same level. The similarity tree, shown in Additional file 8, C, revealed a somewhat stronger relationship between biological replicates of the WT genotype and that of $\operatorname{cog} 7 \Delta$ genotype than the remaining ones. Thus, it seems that evolutionary trajectories of WT and $\operatorname{cog} 7 \Delta$ populations were convergent, while the remaining ones were more distinct. However, in general, the prevalent similarity between replicates of a given genotype in combination with transcriptomic data abundance prompted us to pool data gathered for 
individual replicates to show strain-specific changes. Complete adaptive transcriptome results (see Additional file 9) were subject to several analyses.

Having found the differences of adaptive transcriptomes between genotypes, as the next step we performed the gene ontology (GO) analysis of identified genes that were differentially expressed between genotypes. This analysis allowed us to determine the functions of these genes and to assess the potential compensatory capacity of the observed changes in their expression. A given gene was considered as differentially expressed if its expression had changed at least twofold $(\log 2$ ratio $\geq 1$, or $\leq-1)$ in at least two of three biological replicates. The microarray data were validated for several DEGs by RT-qPCR giving excellent correspondence of the two sets of results (Additional file 10).

We found significant changes in the mRNA level for $7.7 \%$ of genes in the evolved wild-type, $6 \%$ in the evolved $\operatorname{cog} 7 \Delta$ and $2.9 \%$ the evolved nup $133 \Delta$ and for the mutator strains: $9.4 \%$ in $m s h 2 \Delta, 4.6 \%$ in $\operatorname{cog} 7 \Delta$ $m s h 2 \Delta$, and $4.3 \%$ in nup $133 \Delta m s h 2 \Delta$. The results (summarized in Additional file 11) were then analyzed in the context of the interaction network fitness landscape with the assumption that downregulation of gene expression can mimic its loss-of-function (Table 5).

Table 5 shows the impact of the genes exhibiting altered expression levels during compensatory evolution on the fitness of the deletion mutants assayed according to the genetic interaction network fitness landscape. Notably, upregulation was more common than downregulation for those genes whose inactivation was predicted to have a negative impact on fitness. For instance, in the evolved $\operatorname{cog} 7 \Delta$ strain, out of the total of 57 DEGs whose absence should be deleterious according to the fitness landscape data as many as 45 were upregulated. Moreover, according to evolutionary theories, the level of fixation of deleterious mutations is very low. Thus, it could be expected that mutations leading to down-regulation of genes with a predicted deleterious effect of inactivation are very rare. In

Table 5 Mutations in ORFs of evolved non-mutator and mutator populations, grouped according to their predicted effect

\begin{tabular}{|c|c|c|c|c|}
\hline \multirow{2}{*}{ Evolved strain } & \multicolumn{4}{|l|}{ Protein effect } \\
\hline & Substitution & Frameshift & Truncation & None \\
\hline $\operatorname{cog} 7 \Delta$ evo_1 & BUL1; HOG1 & & & \\
\hline $\operatorname{cog} 7 \Delta$ evo_2 & & & & DAN4 \\
\hline $\operatorname{cog} 7 \Delta$ evo_3 & MEC1 & & & \\
\hline nup133s evo_1 & CAN1; PFK27 & & WHI2 & \\
\hline nup133s evo_2 & BUL1; DAN4; WHI2 & & & \\
\hline \multicolumn{5}{|l|}{ nup133s evo_3 } \\
\hline WT evo_1 & MSY1 & HOG1 & & \\
\hline WT evo_2 & HOG1 & & URE2 & DAL82 \\
\hline WT evo_3 & MSY1 & & & \\
\hline $\operatorname{cog} 7 \Delta$ msh2 $\Delta$ evo_1 & IRR1; PIF1; SEO1; SHP1; WAR1; YPL277C & & & CDC3; YER010C \\
\hline $\operatorname{cog} 7 \Delta$ msh2 $\Delta$ evo_2 & $\begin{array}{l}\text { AMF1; ELM1; GLN1; HUR1; KRE5; } \\
\text { MRPS5; PAB1; PMR1; PRP2; SEO1; } \\
\text { SHM2; SKM1; SOL4; SSN3; TKL1; TRX2 }\end{array}$ & & ECM21; SAP30 & $\begin{array}{l}\text { CDC3; ISW2; } \\
\text { NRD1; YPS1 }\end{array}$ \\
\hline $\operatorname{cog} 7 \Delta$ msh2 $\Delta$ evo_3 & $\begin{array}{l}\text { AMN1; ART5; DAK2; DMA2; EXO5; GNA1; } \\
\text { HSP104; HXK1; ICL1; NET1; PRO3; } \\
\text { RPL4B; SEO1; YPL247C }\end{array}$ & & ACE2; & CDC3; PEX7; VHS3 \\
\hline nup133s msh2 $\Delta$ evo_1 & $\begin{array}{l}\text { APC5; CAN1; DMA1; EFT2; GIC1; INP1; } \\
\text { PEX21; SAM2; SLA2; SWI1 }\end{array}$ & & & $\begin{array}{l}A D Y 3 ; B D P 1 ; \\
D C K 1 ; E G H 1 ; \\
\text { SRC1; TIP1 }\end{array}$ \\
\hline nup133 $13 s h 2 \Delta$ evo_2 & ACC1; EMP65; GEX1; IBA57; PRK1 & & & $\begin{array}{l}\text { CDC43; GEX1; } \\
\text { RGT2; YRB30 }\end{array}$ \\
\hline 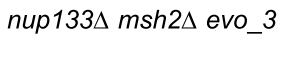 & $\begin{array}{l}\text { BRE1; CEX1; HSP60; RSC1; SCW4; } \\
\text { YLR177W }\end{array}$ & & MEC3; RIM15; TAH1 & FLO11; RIX7; SRB8 \\
\hline msh2 $\Delta$ evo_2 & PMD1 & & URE2 & \\
\hline msh2 $\Delta$ evo_3 & $\begin{array}{l}\text { BRR2; DRN1; MDN1; PRO3; RPL42B; } \\
\text { URE2; YBT1 }\end{array}$ & & & \\
\hline
\end{tabular}


Table 6 Gene expression changes in evolved yeast strains vs. fitness landscape

\begin{tabular}{|c|c|c|c|}
\hline \multicolumn{2}{|c|}{$\begin{array}{l}\text { Impact in the interaction } \\
\text { network }\end{array}$} & Downregulated & Upregulated \\
\hline \multicolumn{4}{|c|}{ Evolution of $\operatorname{cog} 7 \Delta$} \\
\hline \multirow[t]{2}{*}{ On $\operatorname{cog} 7 \triangle^{* *}$} & Deleterious & 12 & 45 \\
\hline & Beneficial & 6 & 2 \\
\hline \multicolumn{4}{|c|}{ Evolution of nup $133 \Delta$} \\
\hline \multirow[t]{2}{*}{ On nup133ム } & Deleterious & 7 & 11 \\
\hline & Beneficial & 3 & 3 \\
\hline \multicolumn{4}{|c|}{ Evolution of $m s h 2 \Delta$} \\
\hline \multirow[t]{2}{*}{ On $m s h 2 \Delta^{* *}$} & Deleterious & 14 & 68 \\
\hline & Beneficial & 24 & 10 \\
\hline \multicolumn{4}{|c|}{ Evolution of $m s h 2 \Delta \operatorname{cog} 7 \Delta$} \\
\hline \multirow[t]{2}{*}{ On $\operatorname{cog} 7 \triangle^{* *}$} & Deleterious & 15 & 62 \\
\hline & Beneficial & 9 & 4 \\
\hline \multirow[t]{2}{*}{ On $m s h 2 \triangle^{* *}$} & Deleterious & 14 & 68 \\
\hline & Beneficial & 21 & 10 \\
\hline \multicolumn{4}{|c|}{ Evolution of $m s h 2 \Delta$ nup $133 \Delta$} \\
\hline \multirow[t]{2}{*}{ On nup 133 } & Deleterious & 4 & 9 \\
\hline & Beneficial & 6 & 4 \\
\hline \multirow[t]{2}{*}{ On msh2 $2 \triangle$} & Deleterious & 13 & 19 \\
\hline & Beneficial & 14 & 9 \\
\hline
\end{tabular}

**Statistically significant ( $p$-value $<0.01$ ) under-representation of deleterious genes that were down-regulated (according to the Fisher exact test)

contrast to this expectation, we observed that still such event is quite frequent (12 of 57).

\section{Genetic interactions vs. transcriptomic changes}

Next, we verified changes in expression levels of the genes encoding components of the molecular machines of which the $\operatorname{Cog} 7$ and Nup133 proteins are a part. We checked if there is any enrichment in downregulated genes exhibiting positive GIs or, conversely, an enrichment in upregulated genes exhibiting negative GIs with COG7, NUP133 or MSH2. Only genes exhibiting positive or negative GIs with COG7, NUP133 or MSH2 were analyzed. However, we did not find enrichment in genes having genetic interactions among DEGs (Table 7).

Moreover, even when the DEGs from the $\operatorname{cog} 7 \Delta$ and $\operatorname{cog} 7 \Delta m s h 2 \Delta$ are analyzed for interactions with the NUP133 gene, or those from nup133A and nup133A $m s h 2 \Delta$ for GIs with COG7, or those not bearing $M S H 2$ deletion for GIs with $M S H 2$, the results show no difference from a random distribution, indicating a lack of correlation between the expression changes and genetic interactions with the original deletion. Similar results were obtained for DEGs of wild-type strain which additionally confirm that evolution of gene expression seems to be independent of genetic interactions. The outcomes of this analysis remain similar regardless of the Costanzo
Table 7 Percentage of DEGs in evolved strains showing genetic interactions (GI) with the COG7, NUP133 or MSH2 gene

\begin{tabular}{|c|c|c|c|}
\hline \multirow[t]{3}{*}{ Evolved strain } & \multicolumn{3}{|c|}{$\begin{array}{l}\text { DEGs exhibiting genetic interactions } \\
\text { with (\%) }\end{array}$} \\
\hline & COG7 & NUP133 & MSH2 \\
\hline & \multicolumn{3}{|c|}{$\begin{array}{l}\text { In accordance with functional } \\
\text { module logic }\end{array}$} \\
\hline $\operatorname{cog} 7 \triangle$ & 3.3 & 2.6 & 0.8 \\
\hline nup1334 & 0.0 & 4.4 & 0.5 \\
\hline wild-type & 1.2 & 2.5 & 0.6 \\
\hline $\operatorname{cog} 7 \Delta m s h 2 \Delta$ & 0.0 & 1.5 & 0.3 \\
\hline nup $133 \Delta$ msh2 & 1.4 & 0.0 & 0.5 \\
\hline msh2 $\triangle$ & 0.6 & 4,0 & 1.2 \\
\hline $\begin{array}{l}\text { No. of genes exhibiting Gls } \\
\text { with deleted gene }\end{array}$ & 175 & 204 & 62 \\
\hline
\end{tabular}

Results of analysis based on Costanzo et al. [16] data when stringent confidence filtration threshold $(P<0.05$ and $\mathrm{GIS}>0.16$ or $<-0.12)$ was applied

et al. [16] data filtration threshold applied [stringent confidence or lenient (data not shown)].

\section{Gene expression profiles in evolved strains-general descriptions of transcriptomes}

At first, to find out whether the mutations identified in the $5^{\prime}$ upstream putative promoter regions directly affected transcription we compared the results of whole-genome sequencing of yeast populations with the observed gene expression changes. We found that there was no apparent correlation between promoter mutations and changes in transcript abundance (Additional file 12).

Next, to find the biological significance of the transcriptomic changes we performed further analyses. To identify DEGs unique to each evolved strain the list of DEGs for each of the mutants and control strains were compared with each other, separately for the down- and upregulated DEGs, and separately for the $\mathrm{MSH} 2$ and msh $2 \Delta$ strains (Fig. 3).

Next, the lists of genotype-specific DEGs were subjected to a GO term enrichment analysis. The results are summarized in Fig. 4, and detailed information concerning top enriched GO terms of DEGs of all strains studied is provided in Additional files 14 and 15.

To sum up, we found that the transcriptomic changes in the evolved strains were mainly associated with adaptations to the culture conditions (e.g., downregulation of genes linked to the biosynthesis of glycerol and amino acids, and upregulation of genes linked to glucose uptake). We did not observe evident changes that might indicate significant alterations in the level of 


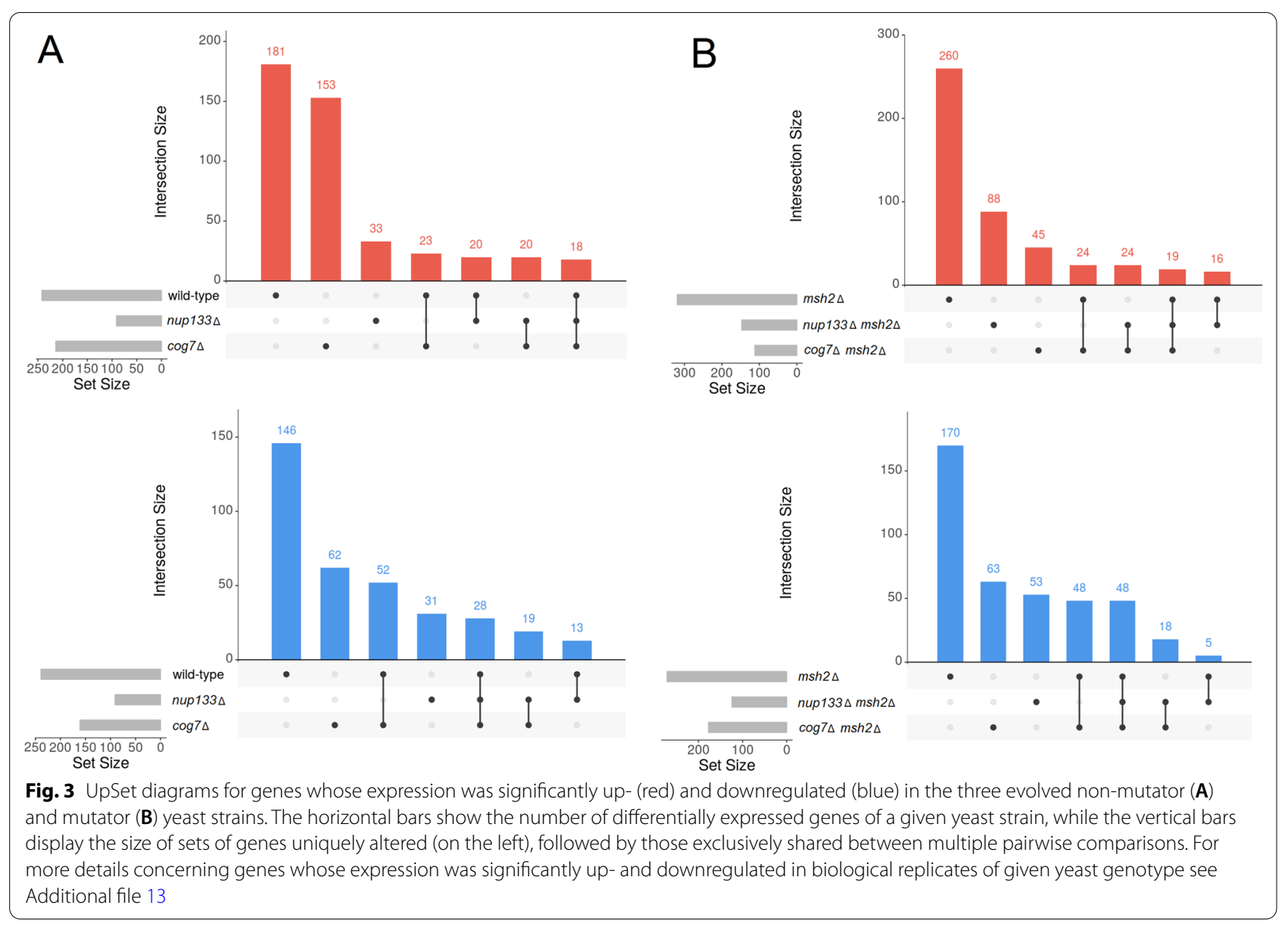

transcription of the genes within COG7 or NUP133 functional modules.

\section{Comparative analysis of evolved strains at the transcriptome level}

To identify a common set of genes that could be differentially expressed in response to the COG7 or NUP133 deletion, unique DEGs of single mutants were compared with those from corresponding double mutants (Fig. 5). $\operatorname{cog} 7 \Delta$ shared seven DEGs with $\operatorname{cog} 7 \Delta m s h 2 \Delta$, and nup $133 \Delta$ shared six DEGs with nup $133 \Delta$ msh $2 \Delta$ in total.

The comparison of the transcriptomic changes in the evolved $m s h 2 \Delta$ and $\operatorname{cog} 7 \Delta$ strains has interesting outcomes. In total 71 DEGs are common for these two strains, of which 16 genes are down and 55 upregulated (the similarity of the upregulated DEG sets is reflected in the $\mathrm{GO}$ analyses). We noticed that the majority of the upregulated DEGs common to these two strains are associated with rRNA modifications and processing as well as with ribosome biogenesis. This is likely a metabolic adjustment to constant substrates availability and invariable growth conditions. However, it is not clear why these two mutants show such similar transcriptomic changes.

To sum up, functional analysis showed a different picture of changes in non-mutator and corresponding mutator strain. Hence, we did not observe sets of gene expression profiles of which can qualitatively assess the common response of the yeast strains to a given gene deletion.

\section{Discussion}

The primary topic investigated in this study was re-examining the assumption that during evolution, nonlethal deleterious mutations are frequently compensated for by other mutations elsewhere in the genome. An earlier study of compensatory evolution following gene deletion in yeast by [8] indicated that the fitness losses caused by deletions are rapidly compensated for by mutations elsewhere in the genome. In particular, frequent compensation through loss-of-function nonsense mutations was observed. Echenique et al. reached a similar conclusion after studying 37 gene deletion mutants [9]. These 


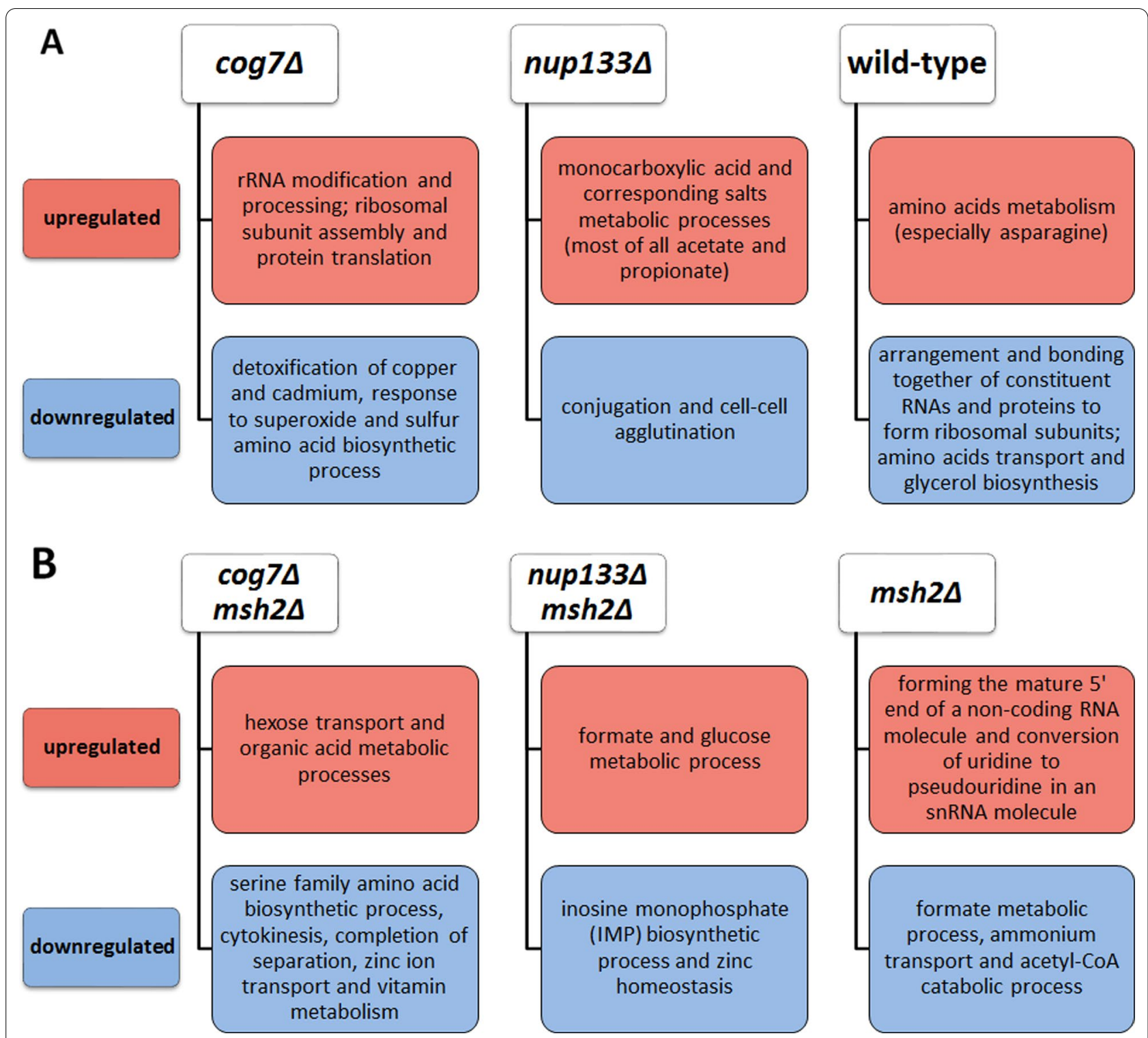

Fig. 4 Enriched GO terms in the biological process category among DEGs from evolved non-mutator $(\mathbf{A})$ and mutator (B) strains

researchers also identified a number of premature stop codons in other genes, which likely cause loss of function. In fact, approximately $20 \%$ of all non-silent mutations identified in the two above studies were putative loss-of-function mutations. These observations complemented other evolutionary experiments with microorganisms (bacteria and yeast), which have demonstrated that the most common adaptive changes are due to the loss or modification of a preexisting molecular function $[32,60-66]$.

The difference between our study and those of others is the scale. Specifically, we subjected two yeast mutants to very detailed examinations, whereas others performed large-scale experiments. We tested strains devoid of the genes COG7 or NUP133 because these genes are prolific interactors, and it was reasonable to expect fairly frequent beneficial inactivation(s) of elements of their networks. The cellular processes in which COG7 and NUP133 are involved are completely unrelated to each other; therefore, any evolutionary pattern found common to the two mutants was likely to be universal. Moreover, since the Cog7 and Nup133 proteins are evolutionarily conserved from yeast to humans, our findings should be valid for other organisms, as well, and our putative findings could be important in many biological aspects, including medicine. 


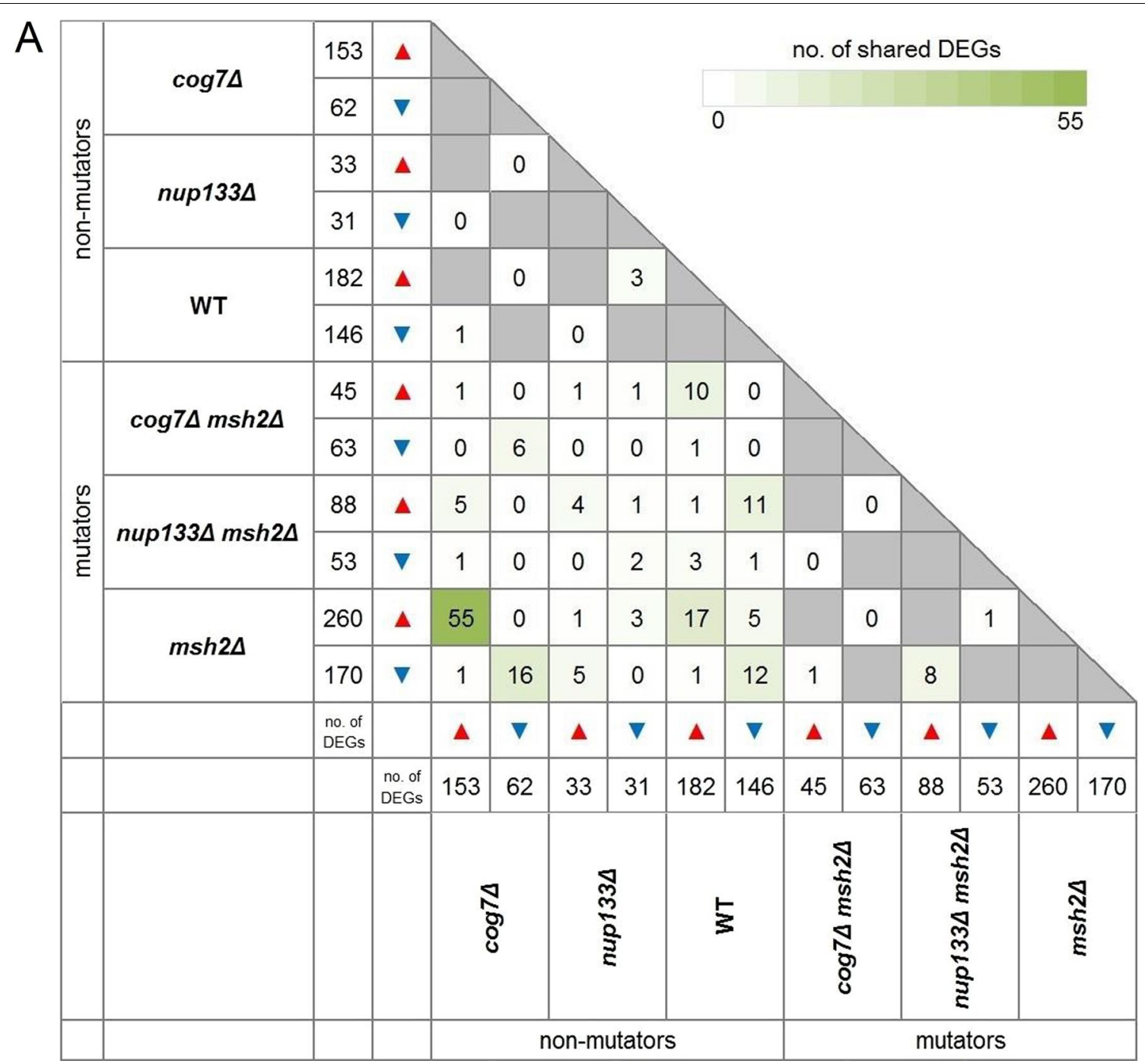

Fig. 5 A DEGs shared by non-mutator and mutator strains. DEG sets unique to a given evolved strain (as determined within the non-mutator (MSH2) and mutator (msh2 $\triangle$ ) set of strains) were compared with one another. Grey cells depict pairs that a priori cannot have common DEGs. Triangles pointing upwards and downwards indicate up- and downregulated DEGs. B Detailed comparison of all yeast strains tested. UpSet diagrams indicate intersections between up- (red) and downregulated (blue) genes in all yeast strains tested, generated by multiple comparisons. The horizontal bars show the number of differentially expressed genes of a given yeast strain, while the vertical bars display the size of sets of genes ordered by increasing degree of intersections

However, neither $\operatorname{cog} 7 \Delta$ nor nup $133 \Delta$ had been tested previously; thus, we could not compare our results to subsets of large data sources.

Notably, our study indicated that the lack of COG7 or NUP133 has an almost negligible impact on elements of modules of genetically interacting genes and on the transcriptional activity of other genes in the modules. Whether this result is a particular case to COG7 and NUP133 or whether the other studies identified only a specific set of modules has not been determined. This study also suggests that the fitness landscape of the genetic interaction network has some impact on the course of compensatory evolution. However, this impact can be observed mainly in transcriptomic experiments.

At the genomic level, we observed putative adaptations to the continuous culture environment, although in our experiments an element of nutritional stress (typical to chemostat) was omitted. This included mutation in the WHI2, RIM15, ACE2 and HOG1 genes which are related to environmental adaptations. Evidently, continuous culture conditions exert a stronger selective pressure than does a gene knockout itself. 


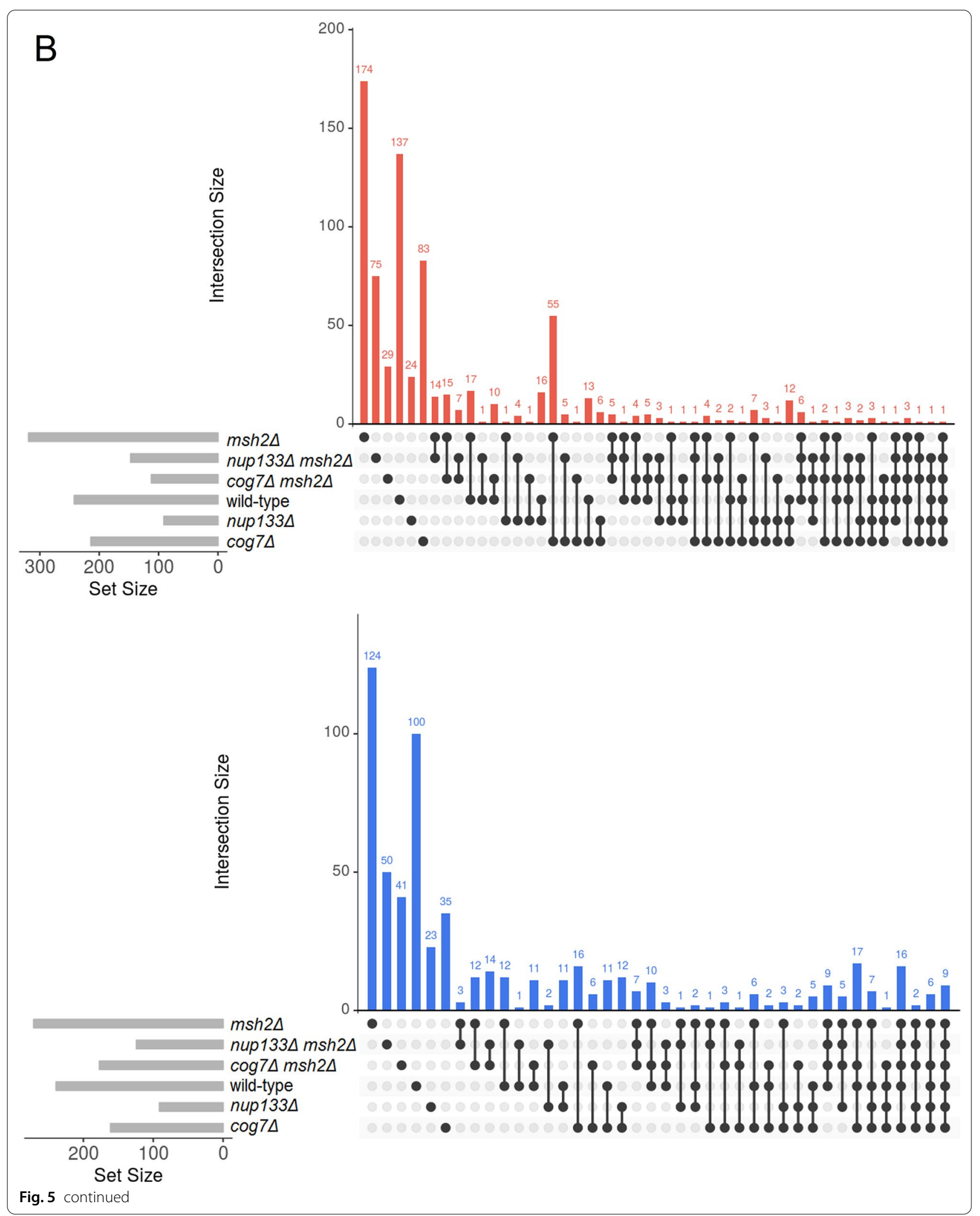


Moreover, because three independently evolved populations derived from a given strain were sequenced, we could search for parallel evolutionary events. Surprisingly, we found only few parallel mutations which indicates that compensatory evolution is not deterministic and can lead to genetic divergence of evolving populations. What is more, the analysis allowed identification of recurrent mutations in BUL1, PRO3, URE2, and HOG1 genes apparently beneficial in our experimental conditions regardless of the genetic background.

We also observed a few mutations that might compensate for the gene deletions assayed (Table 4). We hypothesize that changing the activity of these genes could restore the fitness of $\operatorname{cog} 7 \Delta$ and nup $133 \Delta$. However, these changes are probably related to different mechanisms of fitness compensation or different compensatory events, since they constituted only individual cases and were not repeatable between different biological replicates for a given yeast strain.

The mutations identified in the present study comprised nonsense mutations causing protein truncation and likely depriving of activity, and missense mutations, which could have diverse effects on proteins: enhancing or inhibiting their activity or even modifying their functions and the outcome of such mutations is difficult to predict. However, we found that the majority of missense mutations occurred in genes involved in basic cellular processes. It is not clear why the adaptive landscape associated with these genes is not stable.

We also attempted to determine whether the adaptive landscape reflecting the yeast genetic interaction network is universal and has an impact on the evolution of yeast deletion mutants. We assumed that if the fitness landscape of the genetic interaction network governs the process of compensatory evolution, the loss-of-function mutations should also be beneficial for a given deletion mutant in the fitness landscape. This observation is supported by studies of the WHI2 gene, which was also mutated in one of our experiments. It was shown that the landscape of the deletion of this gene is very unstable. According to the network of Constanzo et al., deletion of WHI2 is neutral or slightly deleterious. This finding was confirmed in the study of Szamecz et al. [8], who found that the WHI2 deletion is very weakly deleterious; these researchers also found a compensatory effect of WHI2 inactivation during evolution of a $r p b 9 \Delta$ strain. In contrast, in other environmental conditions (in dense colonies and upon nutrient deprivation), deletion of WHI2 is beneficial [67]. In unstable landscapes, loss-of-function mutations of WHI2 are frequently observed [68].

In microevolution studies, the analysis of transcriptome is often the only method used to identify adaptive changes occurring in cell populations [69-72] and only very few studies analyzed changes at both the genome and transcriptome level [55, 73]. Because the reduction of the level of a given mRNA can, to some extent, mimic the effect of the lack of a gene, we carefully examined transcriptomic data. We observed fairly frequent downregulation of genes whose inactivation is predicted to be deleterious according to the fitness landscape of the genetic interaction network. However, these instances of downregulation were underrepresented, which suggested a tendency of the gene expression changes during continuous culture evolution to follow the fitness landscape. Nevertheless, similar to gene mutations, numerous cases of gene downregulation did not conform to the prediction obtained from the known pattern of genetic interactions. Thus, although our experimental approach may have some limitations, this result suggests that the fitness landscape is unstable and may be easily modified by genetic and external factors.

\section{Conclusions}

Our results indicate that the assumption that nonlethal deleterious mutations are frequently compensated for by other mutations in genetically interacting genes during evolution is not universal and, in fact, does not include COG7 and NUP133 yeast genes. Moreover, at the level of gene expression, we noticed that for those genes whose inactivation was predicted to have a negative impact on fitness, the upregulation of transcription is more often observed than downregulation. We tend to think that the adaptive landscape of compensatory evolution is not stable and evolutionary trajectories are unpredictable using landscapes derived for specific conditions. In contrast, general adaptations to given environmental conditions and the landscape of such adaptations are stable. The results obtained with our model indicate that the modular structure of the cellular machinery has a limited impact on short-term evolution in the conditions assessed.

\section{Materials and methods}

\section{Strains and media}

Haploid S. cerevisiae strains used in this study were derivatives of W303 (MATa or MAT $\alpha$ leu2-3,112 trp1-1 can1-100 ura3-1 ade2-1 his3-11,15\}). All primers used are listed in Additional file 16. To construct knockout strains nup $133 \Delta$ and $\operatorname{cog} 7 \Delta, \operatorname{Kan} M X$ cassette conferring resistance to $\mathrm{G} 418$ was amplified from the appropriate yeast deletion collection haploid strains (Euroscarf, Germany), along with 200 bp of both ATG-upstream and stop codon-downstream DNA for homology. Wild-type strain W303 was transformed using the lithium acetate method [74] and transformants were selected for G418 resistance. To construct strains with deleted $\mathrm{MSH} 2$ gene, 
hphMX4 cassette conferring resistance to hygromycin $B$ was amplified from the pAG32 plasmid [75]. Primers contained 45-bp fragments upstream of ATG and downstream of the stop codon for homology. The wild-type and knockout strains were transformed with amplified DNA and transformants were selected for hygromycin B resistance (single mutant $m s h 2 \Delta$ ) or hygromycin B and G418 resistance (double mutants). All knockout strains were verified for correct cassettes integration by PCR and sequencing of PCR-derived fragments. The strains subjected to continuous culture experiments were grown in a complete synthetic liquid medium containing $0.67 \%$ yeast nitrogen base (YNB), $2 \%$ glycerol, $0.1 \%$ yeast extract, $0.1 \%$ glucose and supplemented with the required amino acids and nucleotides. Ampicillin and streptomycin $(25 \mu \mathrm{g} / \mathrm{mL})$ were added to prevent bacterial contamination. For overnight liquid cultures and 2.0\% agar-agar solidified plates YPD medium (1\% Bacto-yeast extract, 2\% Bacto-peptone and $2 \%$ glucose) was used.

\section{Continuous culture evolution experiments}

The evolutionary experiments were conducted in a selfmade continuous culture set based on [76]. Briefly, the chambers, containing $20 \mathrm{~mL}$ of a medium, were made of 50-mL plastic Falcon tubes closed with a silicone stopper pierced with three needles of different lengths. The shortest needle was used to add medium to the chamber. The longest needle reaching to the bottom of the tube provided filtered air (pumped with an aquarium pump) and allowed efficient mixing of cultures. The third needle was used for determining culture volume by removing effluent to collection bottles. To start the experiment $15 \mathrm{~mL}$ of liquid YPD medium was inoculated with a single colony and grown overnight at $30^{\circ}$. Aliquots of the overnight cultures were inoculated into growth chambers to $\mathrm{OD}_{600}=0.1$. After ca. $40 \mathrm{~h}$, the flow of medium was turned on at a dilution rate of $0.17-0.18 \mathrm{vol} / \mathrm{h}$. Each strain was cultivated in triplicate. In total, 18 chambers were inoculated. Culture samples were passively collected every week from fresh effluent for ca. 200 generations (non-mutator strains) or for ca. 350 generations (mutator strains) and stored as dry cell pellets and glycerol stocks at $-80^{\circ}$. Throughout the experiment, vessels were monitored for contamination and formation of flocculants. An experiment was terminated when cell clumps precluded efficient mixing of the culture.

\section{Whole-genome population sequencing (WGS) and sequence analysis}

Population genomic DNA was extracted from dry, frozen cell pellets using Bacterial \& Yeast Genomic DNA Purification Kit (EurX). DNA quality and quantity were checked by agarose gel electrophoresis and fluorimetric measurements with Qubit dsDNA BR Assay Kit (Thermo Fisher Scientific). Then the DNA was mechanically sheared to an appropriate size and used for paired-end library preparation using KAPA Library preparation kit (Roche) following the manufacturer's instructions and sequenced in the paired-end mode $(2 \times 300 \mathrm{bp})$ on a MiSeq (Illumina) instrument. The sequencing was performed at the DNA Sequencing and Oligonucleotide Synthesis Laboratory of the Institute of Biochemistry and Biophysics PAS, Warsaw, Poland. Sequencing data were filtered by quality using fastp toolkit [77]. The average sequence coverage from WGS of the yeast populations was targeted at around $100 \times$. Progenitor strain reads were aligned against the genome sequence of W303 [78] to build a progenitor consensus genome for each genetic background. The reads were mapped to the W303 sequence using BWA-MEM [79] and genome sequence alignment was corrected using Pilon [80] with the "fix all" option to correct all point mutations, indels, gaps and fix local misassemblies. Ten iterations of the above polishing scheme were run. Progenitor consensus genomes were annotated according to their Illumina reads and mapped to the appropriate progenitor genome consensus using BWA-MEM, followed by processing using SAMtoolsmpileup [81]. Variant calling was performed using VarScan v2.3.9 [82] with a minimum variant allele frequency threshold set to $50 \%$. From that point the data were handled with Geneious v10.2.6 software (http://www.genei ous.com/). De novo mutational events were identified as alterations from the ancestral strains found in the evolved yeast populations. For that, point mutations and small indels calling were performed with the following options: minimum of ten reads and 50\% mutation threshold frequency. Finally, mutations unique to the evolved populations were identified and verified by visual examination directly in Geneious. Variations at ambiguous positions in the sequence were ignored. Selected mutations localized to ORFs were validated in populations using PCR with appropriate primer pairs (Additional file 16) and DNA sequencing.

\section{DNA content analysis by flow cytometry}

The DNA content of yeast cells was measured by flow cytometry as previously described [83], with modifications restricting cells aggregations. About $10^{7}$ cells from initial and final yeast cultures were spun down $(19,300 \mathrm{~g}$ for $1 \mathrm{~min}$ ) and subjected to permeabilization and fixation via suspension in $1 \mathrm{ml}$ of chilled $\left(-20^{\circ} \mathrm{C}\right) 80 \%$ ethanol (Polmos, Warsaw, Poland). Cells suspensions were held at room temperature for at least $2 \mathrm{~h}$. The fixed cells were then washed twice in FACS buffer $[0.2 \mathrm{M}$ Tris$\mathrm{HCl}$ (Sigma-Aldrich) pH 7.4 and 20 mM EDTA (Merck, Darmstadt, Germany)] and incubated at $37{ }^{\circ} \mathrm{C}$ for $2 \mathrm{~h}$ 
in FACS buffer with $1 \mathrm{mg} / \mathrm{ml}$ RNase A (Sigma-Aldrich). After removal of cellular RNA, cells were washed with sodium citrate buffer $(50 \mathrm{mM} \mathrm{pH} 7.2)$ and incubated at $55{ }^{\circ} \mathrm{C}$ for $1 \mathrm{~h}$ in sodium citrate buffer $(50 \mathrm{mM} \mathrm{pH}$ 7.2) with $2 \mathrm{mg} / \mathrm{ml}$ Proteinase K (A\&A Biotechnology) to remove proteins. Then, the cells were washed with phosphate buffered saline (PBS) and stained overnight at $4{ }^{\circ} \mathrm{C}$ in the dark with $100 \mu \mathrm{l}$ of propidium iodide solution $(50 \mu \mathrm{g} / \mathrm{ml}$ in PBS; Calbiochem). After the addition of $900 \mu \mathrm{l}$ of PBS, EDTA was added to a final concentration $20 \mathrm{mM}$, and the cells were sonicated at least three times for $15 \mathrm{~s}$ each using Microson XL Ultrasonic Cell Disruptor (Misonix), to avoid cell clumping, just before flow cytometry analysis of the DNA content. This analysis was performed with a FACSCalibur analyzer (Becton-Dickinson, Franklin Lakes, NJ). A total of 10,000 cells in each sample were counted.

\section{Preparation of total RNA and transcriptome analysis}

Total RNA was extracted from frozen yeast cell samples obtained from $5 \mathrm{~mL}$ of continuous culture using the acid phenol-chloroform procedure [74]. The quantity and quality of the RNA preparations were tested with the 2100 Bioanalyzer expert assay RNA Nano (Agilent Technologies). Transcriptomes of the evolved cell populations were compared with that of the original one using Yeast (v2) Gene Expression $8 \times 15 \mathrm{~K}$ Microarray slides (Agilent Technologies) containing oligonucleotides that representing all known $S$. cerevisiae genes identified in the SGD. cDNA probes labeled with Cy3 or Cy5 fluorescent dyes were synthesized using the Agilent Two-Color Quick Amp Labeling Kit according to the manufacturer's protocol, with total RNA preparations as the template. The labeled probes were hybridized concurrently to microarrays. Three biological replicates were run, each with two technical replicates with dye-swap. The resulting fluorescence images were scanned with an Axon GenePix 4000B (Molecular Devices) microarray scanner. Feature extraction was done with GenePix Pro 6.1. Raw data were normalized, technical replicates were averaged, and subjected to statistical analysis with Acuity 4.0 software. Additional data manipulations were done in Microsoft Excel. For each gene, the $\log 2$ ratio of its transcript level in each evolved population to that in the preadapted culture was calculated. Genes displaying $\log 2$ ratio $\geq 1$ or $\leq-1$ in at least two of three biological replicates for a given cell population genotype were considered differentially expressed (DEGs) and were subjected to further bioinformatic analysis. UpSet diagrams were generated using an Intervene online tool [84]. To classify the functions of the identified DEGs, GO analysis was conducted using a Cytoscape (v3.7.2) plugin BiNGO [85] and GO Slim Term Mapper (https://www.yeastgenome.org/goSli
mMapper). Euclidean distances were calculated with the following $\sqrt{\left(p_{1}-q_{1}\right)^{2}+\left(p_{2}-q_{2}\right)^{2}+\cdots+\left(p_{n}-q_{n}\right)^{2}}$, where $p$ and $q$ are $\log 2$ ratios for each gene in two transcriptomes being compared and $n$ is the number of genes. Cluster analysis and the similarity tree visualization was done on the whole transcriptome data using Cluster 3.0 [86] and Java TreeView [87] software, respectively.

Reverse transcription-quantitative PCR (RT-qPCR) analyses To validate the microarray results the RT-qPCR was performed in triplicate using QUANTUM EvaGreen ${ }^{\circledR}$ PCR Kit (Syngen Biotech) according to the manufacturer's instructions and a Mic Real-Time Cycler (Bio Molecular Systems). The primers used (Additional file 16) were based on qPrimerDB (version 1.2) data. Primer specificity was verified by melting curve analysis. Each $20 \mu \mathrm{l}$ reaction mixture contained $4 \mu \mathrm{l}$ of QUANTUM EvaGreen ${ }^{\circledR}$ PCR Kit mix, two primers (4 pmol each) and $1 \mu \mathrm{l}$ of template cDNA. The cDNA was synthesized from 240 ng of total RNA treated with TURBO ${ }^{\mathrm{TM}}$ DNase (Invitrogen) using smART First Strand cDNA Synthesis kit (EurX) according to supplier's protocol. The qPCR reactions were carried out at the following conditions: $95^{\circ}$ for $15 \mathrm{~min}$, followed by 40 cycles of $95^{\circ}$ for $15 \mathrm{~s}, 51.5^{\circ}$ for $20 \mathrm{~s}$ and $72^{\circ}$ for $20 \mathrm{~s}$. The value of crossing threshold cycles (Cq) was determined using the micPCR software v2.8.10. Pfaffl method [88] was applied to calculate relative expression with respect to that of $A C T 1$ that was used as the normalization reference for target gene expression. Then, the fold difference of the gene expression levels between evolved and starting populations, corrected for efficiency, was calculated.

\section{Supplementary Information}

The online version contains supplementary material available at https://doi. org/10.1186/s12862-021-01830-9.

Additional file 1. Doubling times and growth rates of yeast strains studied.

Additional file 2. DNA content analysis of the ancestral (START) and evolved (END) yeast populations. Flow cytometry profiles indicate that short-term continuous culturing experiments did not cause changes in ploidy as all yeast populations studied remain haploid. Control haploid and diploid strains are shown on the right.

Additional file 3. Mutations in ORFs of evolved non-mutator strains, grouped according to their predicted effect.

Additional file 4. Mutations in ORFs of evolved mutator strains, grouped according to their predicted effect.

Additional file 5. Detailed description of mutations identified in evolved yeast strains.

Additional file 6. Extended characteristics of nonsynonymously mutated genes of evolved $\operatorname{cog} 7 \Delta \mathrm{msh} 2 \Delta$ strain. 
Additional file 7. Extended characteristics of nonsynonymously mutated genes of evolved nup $133 \triangle$ msh $2 \Delta$ strain.

Additional file 8. The similarities of the adaptive transcriptomes of all biological replicates of continuous cultures performed in this study, expressed as Euclidean distance parameter and similarity tree obtained after clustering of all transcriptome data.

Additional file 9. Microarray data on all evolved yeast populations subjected to analysis.

Additional file 10. Comparison of changes in transcript levels determined by microarray hybridization with RT-qPCR quantification for selected genes.

Additional file 11. Number of DEGs for each biological replicate and total number of DEGs for each evolved yeast strain.

Additional file 12. Correlation of point mutations located to ORF, and putative promoter and terminator regions and transcriptomic changes in evolved yeast strains

Additional file 13. UpSet diagrams for genes whose expression was significantly up- (red) and downregulated (blue) in the three evolved biological replicates of given yeast genotype.

Additional file 14. Top enriched GO terms of differentially expressed genes for all strains studied. Only the enriched GO terms of "biological process" and "cellular component" categories were analyzed.

Additional file 15. Comments to Additional file 14.

Additional file 16. Primers used in this study.

\section{Acknowledgements}

Not applicable.

\section{Authors' contributions}

SK and UZ conceived and designed the study. JK conducted the experiments, analyzed the data. MS conducted and analyzed transcriptomic experiments. AS performed DNA content analysis by flow cytometry. JK, UZ, MS, AK and SK wrote the manuscript. All authors read and approved the final manuscript.

\section{Funding}

This work was supported by grants (2018/29/N/NZ2/00902 to J.K. and 2014/13/B/NZ8/04719 to S.K.) from the Polish National Science Centre.

\section{Availability of data and materials}

All strains are available upon request. The authors affirm that all data necessary for confirming the conclusions of the article are present within the article and its additional files. Complete WGS data have been deposited in the GenBank under the BioProject ID PRJNA694549. Complete transcriptome analysis data are deposited in the Gene Expression Omnibus (https://www.ncbi.nlm.nih. gov/geo) under accession number GSE167397.

\section{Declarations}

\section{Ethical approval and consent to participate}

Not applicable.

\section{Consent for publication}

Not applicable.

\section{Competing interests}

The authors declare that they have no competing interests.

\section{Author details}

${ }^{1}$ Department of Microbial Biochemistry, Institute of Biochemistry and Biophysics, Polish Academy of Sciences, Pawińskiego 5a, 02-106, Warsaw, Poland. ${ }^{2}$ Department of Genetics, Institute of Biochemistry and Biophysics, Polish Academy of Sciences, Pawińskiego 5a, 02-106, Warsaw, Poland. ${ }^{3}$ Laboratory of Mutagenesis and DNA Repair, Institute of Biochemistry and Biophysics, Polish Academy of Sciences, Pawińskiego 5a, 02-106, Warsaw, Poland.
${ }^{4}$ Department of Bioinformatics, Institute of Biochemistry and Biophysics, Polish Academy of Sciences, Pawińskiego 5a, 02-106, Warsaw, Poland.

Received: 4 November 2020 Accepted: 19 May 2021

Published online: 26 May 2021

\section{References}

1. Fisher RA. The genetical theory of natural selection: a complete variorum edition. Oxford: Oxford University Press; 1930.

2. Wright $\mathrm{S}$. The roles of mutation, inbreeding, crossbreeding, and selection in evolution. 1932. p. 355-66. http://www.esp.org/books/6th-congress/ facsimile/contents/6th-cong-p356-wright.pdf.

3. Arnold SJ, Pfrender ME, Jones AG. The adaptive landscape as a conceptual bridge between micro- and macroevolution. Genetica. 2001;112:932. https://doi.org/10.1023/A:1013373907708.

4. LaBar T, Phoebe Hsieh Y-Y, Fumasoni M, Murray AW. Evolutionary repair experiments as a window to the molecular diversity of life. Curr Biol. 2020;30:R565-74. https://doi.org/10.1016/j.cub.2020.03.046.

5. Boone C, Bussey $\mathrm{H}$, Andrews BJ. Exploring genetic interactions and networks with yeast. Nat Rev Genet. 2007;8:437-49. https://doi.org/10.1038/ nrg2085.

6. Doniger SW, Kim HS, Swain D, Corcuera D, Williams M, Yang S-P, et al. A catalog of neutral and deleterious polymorphism in yeast. PLoS Genet. 2008;4:e1000183. https://doi.org/10.1371/journal.pgen.1000183.

7. MacArthur DG, Balasubramanian S, Frankish A, Huang N, Morris J, Walter $\mathrm{K}$, et al. A systematic survey of loss-of-function variants in human proteincoding genes. Science. 2012;335:823-8. https://doi.org/10.1126/science. 1215040.

8. Szamecz B, Boross G, Kalapis D, Kovács K, Fekete G, Farkas Z, et al. The genomic landscape of compensatory evolution. PLoS Biol. 2014;12:e1001935. https://doi.org/10.1371/journal.pbio.1001935.

9. Echenique JIR, Kryazhimskiy S, Ba ANN, Desai MM. Modular epistasis and the compensatory evolution of gene deletion mutants. PLoS Genet. 2019;15:e1007958. https://doi.org/10.1371/journal.pgen.1007958.

10. Korona R. Experimental studies of deleterious mutation in Saccharomyces cerevisiae. Res Microbiol. 2004;155:301-10. https://doi.org/10.1016/j. resmic.2004.01.015.

11. Covert AW, Lenski RE, Wilke CO, Ofria C. Experiments on the role of deleterious mutations as stepping stones in adaptive evolution. PNAS. 2013;110:E3171-8. https://doi.org/10.1073/pnas.1313424110.

12. Cowperthwaite MC, Bull JJ, Meyers LA. From bad to good: fitness reversals and the ascent of deleterious mutations. PLoS Comput Biol. 2006 https://doi.org/10.1371/journal.pcbi.0020141.

13. Bosshard L, Dupanloup I, Tenaillon O, Bruggmann R, Ackermann M, Peischl $\mathrm{S}$, et al. Accumulation of deleterious mutations during bacterial range expansions. Genetics. 2017;207:669-84.

14. Daran-Lapujade P, Daran J-M, van Maris AJA, de Winde JH, Pronk JT. Chemostat-based micro-array analysis in baker's yeast. Adv Microb Physiol. 2009;54:257-311.

15. Klim J, Zielenkiewicz U, Kurlandzka A, Kaczanowski S, Skoneczny M. Slow adaptive response of budding yeast cells to stable conditions of continuous culture can occur without genome modifications. Genes (Basel). 2020. https://doi.org/10.3390/genes11121419.

16. Costanzo M, VanderSluis B, Koch EN, Baryshnikova A, Pons C, Tan G, et al. A global genetic interaction network maps a wiring diagram of cellular function. Science. 2016;353:aaf1420. https://doi.org/10.1126/science. aaf1420.

17. Smith RD, Lupashin W. Role of the conserved oligomeric Golgi (COG) complex in protein glycosylation. Carbohydr Res. 2008;343:2024-31. https://doi.org/10.1016/j.carres.2008.01.034

18. Quental R, Azevedo L, Matthiesen R, Amorim A. Comparative analyses of the conserved oligomeric Golgi (COG) complex in vertebrates. BMC Evol Biol. 2010;10:212.

19. Belgareh N, Rabut G, Baï SW, van Overbeek M, Beaudouin J, Daigle N, et al. An evolutionarily conserved NPC subcomplex, which redistributes in part to kinetochores in mammalian cells. J Cell Biol. 2001;154:1147-60.

20. Berke IC, Boehmer T, Blobel G, Schwartz TU. Structural and functional analysis of Nup133 domains reveals modular building blocks of the nuclear pore complex. J Cell Biol. 2004;167:591-7. 
21. Oughtred R, Stark C, Breitkreutz B-J, Rust J, Boucher L, Chang C, et al. The BioGRID interaction database: 2019 update. Nucleic Acids Res. 2019:47:D529-41.

22. Willett R, Ungar D, Lupashin V. The Golgi puppet master: COG complex at center stage of membrane trafficking interactions. Histochem Cell Biol. 2013;140:271-83.

23. Fotso P, Koryakina Y, Pavliv O, Tsiomenko AB, Lupashin W. Cog1p plays a central role in the organization of the yeast conserved oligomeric golgi complex. J Biol Chem. 2005;280:27613-23. https://doi.org/10.1074/jbc. M504597200

24. Ha JY, Pokrovskaya ID, Climer LK, Shimamura GR, Kudlyk T, Jeffrey PD, et al. Cog5-Cog7 crystal structure reveals interactions essential for the function of a multisubunit tethering complex. PNAS. 2014;111:15762-7. https://doi.org/10.1073/pnas.1414829111.

25. Lutzmann M, Kunze R, Buerer A, Aebi U, Hurt E. Modular self-assembly of a Y-shaped multiprotein complex from seven nucleoporins. EMBO J. 2002;21:387-97.

26. Siniossoglou S, Wimmer C, Rieger M, Doye $V$, Tekotte $H$, Weise $C$, et al. A novel complex of nucleoporins, which includes Sec13p and a Sec13p homolog, is essential for normal nuclear pores. Cell. 1996;84:265-75. https://doi.org/10.1016/S0092-8674(00)80981-2.

27. Doye $V$, Wepf R, Hurt EC. A novel nuclear pore protein Nup133p with distinct roles in poly $(A)+$ RNA transport and nuclear pore distribution. EMBO J. 1994;13:6062-75.

28. Pemberton LF, Rout MP, Blobel G. Disruption of the nucleoporin gene NUP133 results in clustering of nuclear pore complexes. Proc Natl Acad Sci U S A. 1995;92:1187-91.

29. Bolhy S, Bouhlel I, Dultz E, Nayak T, Zuccolo M, Gatti X, et al. A Nup133dependent NPC-anchored network tethers centrosomes to the nuclear envelope in prophase. J Cell Biol. 2011;192:855-71.

30. Gerstein AC, Chun H-JE, Grant A, Otto SP. Genomic convergence toward diploidy in Saccharomyces cerevisiae. PLoS Genet. 2006;2:e145.

31. Gerstein AC, Otto SP. Cryptic fitness advantage: diploids invade haploid populations despite lacking any apparent advantage as measured by standard fitness assays. PLoS ONE. 2011;6:e26599. https://doi.org/10. 1371/journal.pone.0026599.

32. Venkataram S, Dunn B, Li Y, Agarwala A, Chang J, Ebel ER, et al. Development of a comprehensive genotype-to-fitness map of adaptation-driving mutations in yeast. Cell. 2016;166:1585-1596.e22

33. Gerstein AC, Sharp NP. The population genetics of ploidy change in unicellular fungi. FEMS Microbiol Rev. 2021. https://doi.org/10.1093/femsre/ fuab006.

34. Wickner RB. [URE3] as an altered URE2 protein: evidence for a prion analog in Saccharomyces cerevisiae. Science. 1994;264:566-9.

35. Ideker T, Krogan NJ. Differential network biology. Mol Syst Biol. 2012;8:565. https://doi.org/10.1038/msb.2011.99.

36. Ryan CJ, Roguev A, Patrick K, Xu J, Jahari H, Tong Z, et al. Hierarchical modularity and the evolution of genetic interactomes across species. Mol Cell. 2012;46:691-704. https://doi.org/10.1016/j.molcel.2012.05.028.

37. Koch EN, Costanzo M, Bellay J, Deshpande R, Chatfield-Reed K, Chua G, et al. Conserved rules govern genetic interaction degree across species. Genome Biol. 2012;13:R57. https://doi.org/10.1186/gb-2012-13-7-r57.

38. Antebi A, Fink GR. The yeast $\mathrm{Ca}(2+)$-ATPase homologue, PMR1, is required for normal Golgi function and localizes in a novel Golgi-like distribution. Mol Biol Cell. 1992;3:633-54.

39. Dürr G, Strayle J, Plemper R, Elbs S, Klee SK, Catty P, et al. The medial-Golgi ion pump Pmr1 supplies the yeast secretory pathway with $\mathrm{Ca} 2+$ and $\mathrm{Mn} 2+$ required for glycosylation, sorting, and endoplasmic reticulumassociated protein degradation. MBoC. 1998;9:1149-62. https://doi.org/ 10.1091/mbc.9.5.1149.

40. Spang A, Schekman R. Reconstitution of retrograde transport from the Golgi to the ER in vitro. J Cell Biol. 1998;143:589-99.

41. Schneiter R, Hitomi M, Ivessa AS, Fasch EV, Kohlwein SD, Tartakoff AM. A yeast acetyl coenzyme A carboxylase mutant links very-long-chain fatty acid synthesis to the structure and function of the nuclear membranepore complex. Mol Cell Biol. 1996;16:7161-72.

42. Wood A, Krogan NJ, Dover J, Schneider J, Heidt J, Boateng MA, et al. Bre1, an E3 ubiquitin ligase required for recruitment and substrate selection of Rad6 at a promoter. Mol Cell. 2003;11:267-74. https://doi.org/10.1016/ S1097-2765(02)00802-X.
43. Cairns BR, Schlichter A, Erdjument-Bromage H, Tempst P, Kornberg RD, Winston F. Two functionally distinct forms of the RSC nucleosomeremodeling complex, containing essential AT Hook, BAH, and bromodomains. Mol Cell. 1999;4:715-23. https://doi.org/10.1016/S1097-2765(00) 80382-2.

44. Smith CL, Horowitz-Scherer R, Flanagan JF, Woodcock CL, Peterson CL. Structural analysis of the yeast SWI/SNF chromatin remodeling complex. Nat Struct Biol. 2003;10:141-5. https://doi.org/10.1038/nsb888.

45. Menon BB, Sarma NJ, Pasula S, Deminoff SJ, Willis KA, Barbara KE, et al. Reverse recruitment: the Nup84 nuclear pore subcomplex mediates Rap1/Gcr1/Gcr2 transcriptional activation. Proc Natl Acad Sci U S A. 2005;102:5749-54. https://doi.org/10.1073/pnas.0501768102.

46. Sarma NJ, Buford TD, Haley T, Barbara-Haley K, Santangelo GM, Willis KA. The nuclear pore complex mediates binding of the Mig1 repressor to target promoters. PLOS ONE. 2011. https://doi.org/10.1371/journal.pone. 0027117.

47. Therizols P, Fairhead C, Cabal GG, Genovesio A, Olivo-Marin J-C, Dujon B, et al. Telomere tethering at the nuclear periphery is essential for efficient DNA double strand break repair in subtelomeric region. J Cell Biol. 2006;172:189-99. https://doi.org/10.1083/jcb.200505159.

48. McGuire AT, Mangroo D. Cex1p is a novel cytoplasmic component of the Saccharomyces cerevisiae nuclear tRNA export machinery. EMBO J. 2007;26:288-300. https://doi.org/10.1038/sj.emboj.7601493.

49. Gresham D, Hong J. The functional basis of adaptive evolution in chemostats. FEMS Microbiol Rev. 2015;39:2-16. https://doi.org/10.1111/15746976.12082.

50. Kvitek DJ, Sherlock G. Whole genome, whole population sequencing reveals that loss of signaling networks is the major adaptive strategy in a constant environment. PLoS Genet. 2013:9:e1000397.

51. Brewster JL, Gustin MC. Hog 1: 20 years of discovery and impact. Sci Signal. 2014;7:re7.

52. Saul DJ, Sudbery PE. Molecular cloning of WHI2, a gene involved in the regulation of cell proliferation in Saccharomyces cerevisiae. J Gen Microbiol. 1985;131:1797-806.

53. Pedruzzi I, Dubouloz F, Cameroni E, Wanke V, Roosen J, Winderickx J, et al. TOR and PKA signaling pathways converge on the protein kinase Rim15 to control entry into G0. Mol Cell. 2003;12:1607-13.

54. Gresham D, Desai MM, Tucker CM, Jenq HT, Pai DA, Ward A, et al. The repertoire and dynamics of evolutionary adaptations to controlled nutrientlimited environments in yeast. PLoS Genet. 2008;4:e1000303. https://doi. org/10.1371/journal.pgen.1000303.

55. Hong J, Gresham D. Molecular specificity, convergence and constraint shape adaptive evolution in nutrient-poor environments. PLoS Genet. 2014;10:e1004041. https://doi.org/10.1371/journal.pgen.1004041.

56. Kao KC, Sherlock G. Molecular characterization of clonal interference during adaptive evolution in asexual populations of Saccharomyces cerevisiae. Nat Genet. 2008;40:1499-504. https://doi.org/10.1038/ng.280.

57. Kvitek DJ, Sherlock G. Reciprocal sign epistasis between frequently experimentally evolved adaptive mutations causes a rugged fitness landscape. PLoS Genet. 2011;7:e1002056.

58. Laabs TL, Markwardt DD, Slattery MG, Newcomb LL, Stillman DJ, Heideman W. ACE2 is required for daughter cell-specific G1 delay in Saccharomyces cerevisiae. Proc Natl Acad Sci USA. 2003;100:10275-80.

59. Hope EA, Amorosi CJ, Miller AW, Dang K, Heil CS, Dunham MJ. Experimental evolution reveals favored adaptive routes to cell aggregation in yeast. Genetics. 2017;206:1153-67.

60. Lang Gl, Rice DP, Hickman MJ, Sodergren E, Weinstock GM, Botstein D, et al. Pervasive genetic hitchhiking and clonal interference in forty evolving yeast populations. Nature. 2013;500:571-4.

61. Bracher JM, de Hulster E, Koster CC, van den Broek M, Daran J-MG, van Maris AJA, et al. Laboratory evolution of a biotin-requiring Saccharomyces cerevisiae strain for full biotin prototrophy and identification of causal mutations. Appl Environ Microbiol. 2017. https://doi.org/10.1128/AEM. 00892-17.

62. Cooper VS, Schneider D, Blot M, Lenski RE. Mechanisms causing rapid and parallel losses of ribose catabolism in evolving populations of Escherichia coli B. J Bacteriol. 2001;183:2834-41.

63. Hottes AK, Freddolino PL, Khare A, Donnell ZN, Liu JC, Tavazoie S. Bacterial adaptation through loss of function. PLoS Genet. 2013;9:e1003617. 
64. Lee M-C, Marx CJ. Repeated, selection-driven genome reduction of accessory genes in experimental populations. PLoS Genet. 2012;8:e1002651.

65. McDonald MJ, Gehrig SM, Meintjes PL, Zhang X-X, Rainey PB. Adaptive divergence in experimental populations of Pseudomonas fluorescens. IV. Genetic constraints guide evolutionary trajectories in a parallel adaptive radiation. Genetics. 2009;183:1041-53.

66. Notley-McRobb L, Ferenci T. Adaptive mgl-regulatory mutations and genetic diversity evolving in glucose-limited Escherichia coli populations. Environ Microbiol. 1999;1:33-43. https://doi.org/10.1046/j.1462-2920. 1999.00002.x.

67. Maršíková J, Pavlíčková M, Wilkinson D, Váchová L, Hlaváček O, Hatáková $L$, et al. The Whi2p-Psr1p/Psr2p complex regulates interference competition and expansion of cells with competitive advantage in yeast colonies. PNAS. 2020;117:15123-31. https://doi.org/10.1073/pnas.1922076117.

68. Comyn SA, Flibotte S, Mayor T. Recurrent background mutations in WHI2 impair proteostasis and degradation of misfolded cytosolic proteins in Saccharomyces cerevisiae. Sci Rep. 2017;7:4183. https://doi.org/10.1038/ s41598-017-04525-8.

69. Ferea TL, Botstein D, Brown PO, Rosenzweig RF. Systematic changes in gene expression patterns following adaptive evolution in yeast. Proc Natl Acad Sci U S A. 1999;96:9721-6.

70. ter Linde JJ, Liang H, Davis RW, Steensma HY, van Dijken JP, Pronk JT. Genome-wide transcriptional analysis of aerobic and anaerobic chemostat cultures of Saccharomyces cerevisiae. J Bacteriol. 1999;181:7409-13.

71. Jansen MLA, Diderich JA, Mashego M, Hassane A, de Winde JH, DaranLapujade P, et al. Prolonged selection in aerobic, glucose-limited chemostat cultures of Saccharomyces cerevisiae causes a partial loss of glycolytic capacity. Microbiology (Reading). 2005;151(Pt 5):1657-69.

72. Kazemi Seresht A, Cruz AL, de Hulster E, Hebly M, Palmqvist EA, van Gulik W, et al. Long-term adaptation of Saccharomyces cerevisiae to the burden of recombinant insulin production. Biotechnol Bioeng. 2013;110:2749-63.

73. Wenger JW, Piotrowski J, Nagarajan S, Chiotti K, Sherlock G, Rosenzweig F. Hunger artists: yeast adapted to carbon limitation show trade-offs under carbon sufficiency. PLoS Genet. 2011;7:e1002202.

74. Lundblad V, Struhl K. Yeast. Curr Protoc Mol Biol. 2008;82:1301-4. https:// doi.org/10.1002/0471142727.mb1300s82.

75. Goldstein AL, McCusker JH. Three new dominant drug resistance cassettes for gene disruption in Saccharomyces cerevisiae. Yeast. 1999:15:1541-53.

76. Miller AW, Befort C, Kerr EO, Dunham MJ. Design and use of multiplexed chemostat arrays. JVis Exp. 2013. https://doi.org/10.3791/50262.
77. Chen S, Zhou Y, Chen Y, Gu J. fastp: an ultra-fast all-in-one FASTQ preprocessor. Bioinformatics. 2018;34:i884-90. https://doi.org/10.1093/bioin formatics/bty560.

78. Matheson K, Parsons L, Gammie A. Whole-genome sequence and variant analysis of W303, a widely-used strain of Saccharomyces cerevisiae. G3 (Bethesda). 2017;7:2219-26. https://doi.org/10.1534/g3.117.040022.

79. Li H. Aligning sequence reads, clone sequences and assembly contigs with BWA-MEM. arXiv: 13033997 [q-bio]. 2013. http://arxiv.org/abs/1303. 3997. Accessed 12 Mar 2020.

80. Walker BJ, Abeel T, Shea T, Priest M, Abouelliel A, Sakthikumar S, et al. Pilon: an integrated tool for comprehensive microbial variant detection and genome assembly improvement. PLoS ONE. 2014;9:e112963. https:// doi.org/10.1371/journal.pone.0112963.

81. Li H, Handsaker B, Wysoker A, Fennell T, Ruan J, Homer N, et al. The Sequence Alignment/Map format and SAMtools. Bioinformatics. 2009;25:2078-9.

82. Koboldt DC, Zhang Q, Larson DE, Shen D, McLellan MD, Lin L, et al. VarScan 2: somatic mutation and copy number alteration discovery in cancer by exome sequencing. Genome Res. 2012;22:568-76.

83. Krol K, Antoniuk-Majchrzak J, Skoneczny M, Sienko M, Jendrysek J, Rumienczyk I, et al. Lack of G1/S control destabilizes the yeast genome via replication stress-induced DSBs and illegitimate recombination. J Cell Sci. 2018. https://doi.org/10.1242/jcs.226480.

84. Khan A, Mathelier A. Intervene: a tool for intersection and visualization of multiple gene or genomic region sets. BMC Bioinform. 2017;18:287. https://doi.org/10.1186/s12859-017-1708-7.

85. Maere S, Heymans K, Kuiper M. BiNGO: a Cytoscape plugin to assess overrepresentation of gene ontology categories in biological networks. Bioinformatics. 2005;21:3448-9.

86. de Hoon MJL, Imoto S, Nolan J, Miyano S. Open source clustering software. Bioinformatics. 2004:20:1453-4.

87. Saldanha AJ. Java Treeview-extensible visualization of microarray data. Bioinformatics. 2004;20:3246-8.

88. Pfaff MW. A new mathematical model for relative quantification in realtime RT-PCR. Nucleic Acids Res. 2001;29:e45.

\section{Publisher's Note}

Springer Nature remains neutral with regard to jurisdictional claims in published maps and institutional affiliations.
Ready to submit your research? Choose BMC and benefit from:

- fast, convenient online submission

- thorough peer review by experienced researchers in your field

- rapid publication on acceptance

- support for research data, including large and complex data types

- gold Open Access which fosters wider collaboration and increased citations

- maximum visibility for your research: over $100 \mathrm{M}$ website views per year

At BMC, research is always in progress.

Learn more biomedcentral.com/submissions 